\title{
Desempenho termo acústico de sistemas construtivos: estudo de ferramentas aplicáveis a verificação da conformidade de habitação multifamiliar segundo requisitos da NBR 15.575/2013
}

\author{
Thermal and acoustical performance of building systems: \\ study of tools that assist NBR15,575/2013 Brazilian \\ building standard compliance assessment
}

Paula Capanema Silva Carneiro ${ }^{1}$, Raquel Diniz Oliveira ${ }^{1}$

\author{
${ }^{1}$ Centro Federal de Educação Tecnológica de Minas Gerais - CEFET MG - Departamento de Engenharia Civil - DEC - \\ 30510-000, Belo Horizonte, MG, Brasil. \\ e-mail: paulinhacapanema@hotmail.com,raqueldiniz@cefetmg.br
}

\begin{abstract}
RESUMO
A NBR 15575/2013 estabelece parâmetros para avaliação do desempenho das habitações brasileiras. Contudo, a definição prévia dos sistemas construtivos dotados do desempenho térmico e acústico exigido tem se mostrado uma escolha insegura por parte dos projetistas. Este trabalho objetivou analisar as soluções construtivas empregadas em habitação de interesse social, localizada em Contagem - MG, visando ao atendimento do desempenho térmico e acústico mínimos, estabelecidos pela NBR 15575/2013. O sistema previamente especificado foi alvenaria estrutural de bloco cerâmico para vedação vertical bem como laje de concreto e telha cerâmica, para o fechamento horizontal. A avaliação do desempenho térmico baseou-se no método simplificado previsto na NBR 15.575/2013, ao passo que, para análise do desempenho acústico, foram aplicados o método de cálculo indicado na norma, bem como, simulação computacional por meio do software Projetus para verificação e comparação dos resultados em face as exigências normativas. O resultado do método simplificado evidenciou necessidade de aumento da capacidade térmica da vedação vertical. Quanto ao desempenho acústico, se fez necessário aumentar o índice de redução sonora (Rw) da parede de geminação entre a salas de habitações distintas. Logo, propôs-se a inclusão de $2,5 \mathrm{~cm}$ de reboco entre a alvenaria e o revestimento de gesso corrido em ambas as faces do sistema fato que possibilitou o atendimento do desempenho termo acústico mínimo. Diferenças ínfimas puderam ser notadas entre os valores obtidos pelo método de cálculo (Rw) e simulação (DnT,w e D2m,nT,w), para a análise do isolamento sonoro. A adoção do Projetus se mostrou relevante para estudos preliminares. Como conclusão, o tratamento acústico e térmico na fase de projeto se mostrou indispensável uma vez que os sistemas testados no presente trabalho demandaram ajustes para adequação aos limites normativos. Desta forma, a análise prévia permite definir soluções construtivas aplicáveis, evitando grandes intervenções de adequação na obra e/ou edificação construída.
\end{abstract}

Palavras-chave: Desempenho termoacústico, Sistemas de vedação, NBR 15.575, Simulação computacional, edificação multifamiliar.

\begin{abstract}
The Brazilian performance building code (NBR 15,575) addresses some requirements to assess the residential sector. However, setting a construction system option that meets this code has proven to be challenging. This study aims to evaluate the thermal and the acoustic performance of a social housing envelope, situated in Contagem-MG (Brazil), according to the minimal limits set by NBR 15,575. Structural masonry of ceramic blocks was selected for vertical sealing as well as concrete (floor-pavement) slab and ceramic tile, for horizontal closure. The NBR 15,575 simplified method was carried out for thermal analyzes whereas acoustic evaluation applied standard calculation and simulation method using Projetus software. Results indicated that the external walls need a thermal capacity improvement and the living room inner wall, which splits both unit apartments, need to increase its sound reduction index (Rw). Therefore, $2.5 \mathrm{~cm}$ of plaster in both sides of wall should solve those problems. After this change proposition, the thermal and acoustic minimal performance
\end{abstract}


standard were achieved. A small variation could be notice between calculation (Rw) and simulation sound insulation results (DnT,w and D2m,nT,w). Projetus is perfectly suitable for preliminary studies. As a conclusion, thermal and acoustic building system assessment in an early stage show to be relevant to foster its compliances adjustments as occurred e.g. in this study. Otherwise, major interventions may be necessary either at building site or after construction ends.

Keywords: Thermal and acoustic performance, Construction systems, NBR 15,575 Brazilian code, Computer simulation, multifamily building.

\section{INTRODUÇÃO}

O domínio acerca do comportamento térmico da envoltória possibilita aos projetistas realizar escolhas mais assertivas no que tange a resposta as variáveis climáticas e ao atendimento das condições mínimas de desempenho da edificação [1]. Outros aspectos relevantes, tais como, o desempenho acústico, estrutural, entre outros, também devem ser ponderados para a definição dos sistemas edilícios. Neste contexto, a norma NBR 15.575/2013 [2] estabelece parâmetros mensuráveis para a avaliação dos desempenhos: lumínico, térmico, acústico, estrutural, e segurança contra ao fogo, das habitações brasileiras.

No Brasil, a especificação dos sistemas construtivos nem sempre é motivada pelo comportamento e/ou desempenho idealizado no projeto. A escolha por sistemas construtivos racionalizados tem sido privilegiada em razão da possibilidade de rápida reposição do déficit de moradias brasileiras, independentemente das condições climáticas [3]. Assim, especialmente para os projetos de habitação de interesse social, que apresentam orçamento mais restrito, os projetistas especificam, tradicionalmente, os sistemas construtivos mais comuns no mercado sem considerar, muitas vezes, a sua conformidade com a normas em vigor [4]. As informações acerca do desempenho dos sistemas convencionais e inovadores ainda são insipientes [5]. Um projeto piloto deu origem a uma inciativa que culminou em um mapa de ruído em determinada região urbana de São Paulo [6] possibilitando auxiliar de forma rápida e fácil o diagnóstico dos problemas sonoros desta região. No que tange a informação térmica, é possível consultar dados para alguns sistemas construtivos [4, 7, 8]. Diante disto, ferramentas para auxílio de tomada de decisão e validação de soluções construtivas se fazem extremamente úteis para o mercado da construção civil no Brasil.

A compulsoriedade da NBR 15.575/2013 estimula o controle de qualidade, desenvolvimento, bem como, a pesquisa e inovação na indústria da construção civil visando a garantia do cumprimento do desempenho exigido além de dispor de um melhor resultado do produto final. Entretanto, a norma de desempenho não tem como objetivo a definição de especificações de sistemas construtivos que poderão ser adotados para alcançar a conformidade estabelecida, uma vez que esses sistemas poderão ser influenciados por muitos fatores, como condições de entorno, posicionamento da edificação no terreno, etc. Inexiste, porém, um referencial contendo as informações relativas ao desempenho térmico, acústico, estrutural e de resistência ao fogo dos materiais e sistemas construtivos utilizados no setor da construção civil brasileiro. O acesso a estes dados poderia auxiliar a correta especificação preliminar para as diversas situações em que o empreendimento poderá estar inserido e, também, conciliar economia e qualidade técnica. Alguns laudos e informações técnicas foram disponibilizados no portal do Ministério das Cidades [5] para algumas soluções construtivas. Assim, o desenvolvimento de pesquisas e trabalhos técnicos nesta área possibilitaria uma ampliação desta base de dados. Neste contexto, insere-se o presente trabalho que objetivou avaliar soluções prévias de um projeto padrão à luz das exigências da NBR 15.575/2013 para o desempenho termo acústico dos sistemas construtivos de uma habitação de interesse social (HIS).

\subsection{Parâmetros normativos para avaliação do desempenho térmico}

O desempenho térmico da envoltória relaciona-se as propriedades termo físicas dos seus materiais e componentes constituintes tais como transmitância térmica $(U)$, atraso térmico, absortância ( $\alpha)$ e/ou refletância à radiação solar, emissividade das superfícies, capacidade térmica $(C T)$, condutividade térmica $(\lambda)$, calor específico e densidade de massa aparente dos materiais. Independentemente das condições de exposição, o edifício deve proporcionar, entre outras qualidades, o conforto térmico dos usuários para desenvolvimento de atividades no ambiente. Assim, os fatores climáticos (temperatura do ar, umidade relativa, velocidade do ar, direção dos ventos, radiação solar, etc.), a implantação (latitude, longitude, orientação do edifício, entre outros), bem como o uso e ocupação (número de ocupantes, tipo das atividades desenvolvidas, isolamento das vestimentas, equipamentos utilizados, taxa de renovação de ar no ambiente, etc.) devem ser levados em consideração na fase de concepção de projeto e especificações [9].

No que tange ao referencial normativo nacional, a NBR 15.220 [10], publicada em 2005 e atualizada 
em 2008, estabeleceu meios para avaliar o desempenho térmico de habitações unifamiliares de interesse social, indicando, também, recomendações técnico-construtivas para o projeto e adequação das edificações ao clima local. Para tanto, desenvolveu-se um mapeamento bioclimático brasileiro no qual o território foi subdivido em oito zonas similares, conforme a posição geográfica, as médias mínimas e máximas de temperatura e a umidade relativa do ar (como a carta de ventos para estruturas). Esta norma apresenta, ainda, equações relevantes para a estimativa de parâmetros térmicos dos sistemas construtivos. Assim, na ausência de dados de medições pode-se estimar a resistência térmica $(\mathrm{R})$ de uma camada homogênea de material sólido a partir da Equação 1, conforme espessura da sua camada (e) e condutividade térmica $(\lambda)$.

$$
\mathrm{R}=\mathrm{e} / \lambda
$$

Para um material constituído de camadas homogêneas e não homogêneas a resistência térmica de superfície a superfície (Rt) pode ser calculada pela Equação 2, considerando a existência de seções com diferentes resistências térmicas $(\mathrm{Ra}, \mathrm{Rb}, \ldots, \mathrm{Rn})$ e áreas $(\mathrm{Aa}, \mathrm{Ab}, \ldots, \mathrm{An})$.

$$
\mathrm{Rt}=\frac{\mathrm{Aa}+\mathrm{Ab}+\ldots+\mathrm{An}}{\frac{A a}{R a}+\frac{A b}{R b}+\ldots+\frac{A n}{R n}}
$$

Já resistência térmica de ambiente a ambiente (RT) é dada pela Equação 3, a partir da consideração da resistência térmica de superficiais externa $\left(\mathrm{R}_{\mathrm{Se}}\right)$ e interna $\left(\mathrm{R}_{\mathrm{Si}}\right)$ além da resistência térmica de superfície a superfície (Rt).

$$
\mathrm{RT}=\mathrm{RSe}+\mathrm{Rt}+\mathrm{RSi}
$$

Neste contexto, a transmitância térmica de ambiente a ambiente (U) será obtida pelo inverso da resistência térmica total de ambiente a ambiente (RT) conforme a Equação 4.

$$
\mathrm{U}=1 / \mathrm{RT}
$$

De forma complementar, a capacidade térmica de um componente (CT), pode ser obtida pela Equação 5, conforme a espessura da camada (e), calor específico do material (c), bem como, a densidade de massa aparente do material $(\rho)$.

$$
\mathrm{CT}=\sum_{\mathrm{i}=1}^{\mathrm{n}} \text { e.c. } \rho
$$

Por outro lado, a capacidade térmica de um componente constituído por camadas homogêneas e não homogêneas é dada pela Equação 6, considerando a capacidade térmica de cada seção (CTa, CTb, ..., CTn) e suas respectivas áreas $(\mathrm{Aa}, \mathrm{Ab}, \ldots, \mathrm{An})$.

$$
\mathrm{CT}=\frac{\mathrm{Aa}+\mathrm{Ab}+\ldots+\mathrm{An}}{\frac{A a}{C T a}+\frac{A b}{C T b}+\ldots+\frac{A n}{C T n}}
$$

De caráter mais amplo e obrigatório, a NBR 15.575, publicada em 2008 e atualizada em 2013, estabeleceu parâmetros mensuráveis para a avaliação do desempenho térmico, acústico, lumínico, estrutural e construtivo em geral como durabilidade (vida útil de materiais e estruturas), segurança contra incêndio, entre outros. Seu método simplificado permite a verificação do atendimento dos limites estabelecidos nas partes 4 e 5 para o sistema de vedação vertical e horizontal (U, CT e $\alpha$ para o quesito térmico), levando em consideração a zona bioclimática em que o empreendimento está inserido conforme zoneamento apresentado na NBR 15.220/2008 [10]. A norma estabelece, ainda, que os ambientes de permanência prolongada, (salas e quartos) devem apresentar aberturas com dimensões adequadas para proporcionar a ventilação interna dos ambientes [2]. Tais exigências foram sintetizadas na Tabela 1 . 
Tabela 1: Limites para avaliação do desempenho térmico (NBR 15.575/2013) [2]).

\begin{tabular}{|c|c|}
\hline SISTEMA EDILÍCIO & LIMITES EXIGIDOS \\
\hline $\begin{array}{l}\text { Vedação vertical } \\
\text { (parede externa) }\end{array}$ & $\begin{array}{l}\left.\text { Referência Mínima: } \mathrm{CT} \geq 130 \mathrm{~kJ} / \mathrm{m}^{2} \mathrm{~K} \text { (ZB1 a } 7\right), \mathrm{U} \leq 2,5 \mathrm{~W} / \mathrm{m}^{2} \mathrm{~K} \text { (ZB1 e } 2 \alpha \text { não aplicável), } \mathrm{U} \leq \\
3,7 \text { (ZB3 a } 8 \text { para } \alpha \leq 0,6) \text { ou } \mathrm{U} \leq 2,5 \text { (ZB3 a } 8 \text { para } \alpha>0,6)\end{array}$ \\
\hline $\begin{array}{l}\text { Vedação horizontal } \\
\text { (cobertura) }\end{array}$ & $\begin{array}{l}\text { Referência Mínima: } U \leq 2,3 \text { (ZB1 e } 2 \alpha \text { não aplicável, ZB3 a } 6 \text { para } \alpha \leq 0,6 \text { e ZB7 e } 8 \text { para } \alpha \leq \\
0,4) \text {. Referência Intermediária: } U \leq 1,5 \text { (ZB1 e } 2 \alpha \text { não aplicável, ZB3 a } 6 \text { para } \alpha \leq 0,6 \text { e ZB7 e } 8 \\
\text { para } \alpha \leq 0,4) \text { ou } U \leq 1,0 \text { (ZB3 a } 6 \text { para } \alpha>0,6 \text { e ZB7 e } 8 \text { para } \alpha>0,4) \text {. Referência Superior: } U \leq \\
0,5 \text { (ZB3 a } 6 \text { para } \alpha>0,6 \text { e ZB7 e } 8 \text { para } \alpha>0,4) \text { ) } U \leq 1,0 \text { (ZB1 e } 2 \alpha \text { não aplicável, ZB3 a } 6 \text { para } \\
\alpha \leq 0,6 \text { e ZB7 e } 8 \text { para } \alpha \leq 0,4) \text {. OBS: Se o ático for ventilado na ZB7 ou 8, deve-se considerar o } \\
\text { fator de ventilação (FV). }\end{array}$ \\
\hline Ventilação natural & $\begin{array}{l}\text { Referência Mínima em percentual de área útil disponível para ventilação em relação a área de } \\
\text { piso de ambiente de permanência prolongada (A). } A \geq 7 \% \text { (ZB1 a } 7), A \geq 8 \%(Z B 8) \text { para a região } \\
\text { Nordeste e Sudeste ou } A \geq 12 \% \text { (ZB8) para o Norte do Brasil. }\end{array}$ \\
\hline
\end{tabular}

Diversos estudos abordaram a avaliação do desempenho térmico em sistemas construtivos conforme os parâmetros estabelecidos pela NBR 15.220 e/ou NBR 15.575 [3, 4, 11-12] demonstrando, em muitos casos, atendimento aos limites estabelecidos para os sistemas testados.

Já o método simulação computacional permite avaliar do comportamento térmico do edifício nos dias típicos de verão e inverno ou reavaliar edificações que obtiveram desempenho insatisfatório pelo método simplificado. De forma complementar, o método informativo permite avaliar o desempenho por meio de medição in loco em edificações existentes, ou protótipos construídos com essa finalidade [2].

Estudos prévios [13-17] indicaram que os resultados obtidos pelo método de simulação da NBR 15.575 (2013) podem mascarar o comportamento real da edificação. Tal situação se configura uma vez que a desconsideração das cargas internas (equipamentos, iluminação e ocupação), a simplificação da ventilação natural (taxa de renovação do volume do ar por hora) associado ao fato deste método indicar um programa de simulação dinâmica para avaliações dos dias típicos podem ocultar condições de desconforto térmico em que os usuários podem estar expostos ao longo de períodos extensos, em diversas semanas e/ou meses do ano. As incertezas associadas à caracterização das propriedades térmicas e físicas dos materiais considerados no processo de simulação computacional podem impactar, significativamente, os resultados referentes ao desempenho térmico de edificação em análise [18]. Assim, para maior precisão, se faz necessária a consulta a uma base de dados mais confiável ou aferição das variáveis relevantes para a caracterização do edifício real por meio de medições em campo e/ou em laboratório para calibração do seu modelo representativo. Este trabalho, no entanto, foca no método simplificado da NBR 15.575 (2013) para a avaliação do desempenho térmico de HIS.

\subsection{Parâmetros normativos para avaliação do desempenho acústico}

No que tange o desempenho acústico, cumpre destacar que o som é o resultado de uma perturbação física ou vibração (onda mecânica) provocada por variação de pressão do meio em relação à pressão atmosférica, propagando-se no meio através da vibração das suas partículas [19]. Desta forma, os ruídos e vibrações podem ser transmitidos tanto pelo ar como pela estrutura. Nas edificações, as principais fontes de ruídos são provenientes do tráfego de veículos local, funcionamento dos estabelecimentos comerciais do entorno, rotina de uso dos vizinhos e das áreas de uso comuns. Neste contexto, se faz necessário prover isolamento acústico adequado por parte das fachadas, coberturas, entrepisos e paredes de geminação que se mostram capazes de inibir grande parcela dos ruídos transmitido entre dois ambientes em uma edificação [20].

Quanto ao referencial normativo nacional, pode-se citar a NBR 10.152/1987, que determinou os níveis de ruído para conforto acústico em ambientes internos, de acordo com o tipo de uso [21], a NBR 12.179/1992, que fixou os critérios para a execução de tratamento acústico em ambientes internos [22], a NBR 10.151/2000, atualizada em 2019, que especificou um método para a medição e quantificação dos níveis de ruído externos à edificação [23] e, também, a NBR 15.575/2013 que acentuou o rigor no cumprimento dos parâmetros abordados anteriormente ao estabelecer, em sua parte 4, critérios para a avaliação do desempenho acústico de habitações [2] conforme se observa na síntese apresentada na Tabela 2. 
Tabela 2: Critério de avaliação do desempenho acústico (NBR 15.575/2013) [2]).

\begin{tabular}{|c|c|c|c|}
\hline TIPO DE RUÍDO & PARÂMETRO ANALISADO & SISTEMA ANALISADO & MÉTODO DE ANÁLISE \\
\hline Som aéreo & $\begin{array}{l}\text { Diferença padronizada de } \\
\text { nível ponderada (DnT,W) e } \\
\text { diferença padronizada de } \\
\text { nível ponderada a } 2 \mathrm{~m} \\
(\mathrm{D} 2 \mathrm{~m}, \mathrm{nT}, \mathrm{w}) .\end{array}$ & $\begin{array}{l}\text { Verificação dos níveis } \\
\text { de isolação sonora das } \\
\text { vedações externas, dos } \\
\text { pisos e paredes internas } \\
\text { no encontro de unidades } \\
\text { habitacionais distintas. }\end{array}$ & $\begin{array}{l}\text { - De engenharia (em campo): conforme } \\
\text { ISO 140/2004 que determina de forma } \\
\text { rigorosa o isolamento acústico global de } \\
\text { vedação; } \\
\text { - Simplificado (em campo): conforme ISO } \\
\text { 10.052/2004, que determina por meio de } \\
\text { uma estimativa o isolamento acústico do } \\
\text { sistema; } \\
\text { - De precisão (em laboratório): conforme } \\
\text { ISO 10.140/2004, para mensuração do } \\
\text { índice de redução sonora ponderado (Rw), } \\
\text { no qual o isolamento sonoro de componen- } \\
\text { tes e elementos são determinados. Assim, } \\
\text { por meio de fórmulas, estima-se os valores } \\
\text { de referência que poderão se traduzir na } \\
\text { potencial resposta global do conjunto. }\end{array}$ \\
\hline Ruído de impacto & $\begin{array}{l}\text { Nível de pressão sonora de } \\
\text { impacto padronizado pon- } \\
\text { derado (L'nT,w) }\end{array}$ & $\begin{array}{l}\text { Determinação do isola- } \\
\text { mento de ruído no sis- } \\
\text { tema de piso, que sepa- } \\
\text { ram unidades habitacio- } \\
\text { nais distintas, resultante } \\
\text { do caminhamento de } \\
\text { pessoas, queda de obje- } \\
\text { tos, entre outros. }\end{array}$ & $\begin{array}{l}\text { - De engenharia (em campo): conforme } \\
\text { ISO 140/2004 que determina de forma } \\
\text { rigorosa o isolamento acústico global de } \\
\text { vedação; } \\
\text { - Simplificado (em campo): conforme ISO } \\
\text { 10.052/2004, que determina por meio de } \\
\text { uma estimativa o isolamento acústico do } \\
\text { sistema. }\end{array}$ \\
\hline
\end{tabular}

De forma complementar, tem-se outras formas de avaliação sonora dos elementos construtivos. Segundo Spannenberg (2006) [17], para o som aéreo em paredes internas cegas (sem a presença de aberturas), "[...] a capacidade de isolamento dos componentes e elementos está relacionada com a sua massa, onde, quanto mais espessa e pesada é uma parede, mais ela isola os ruídos aéreos (Lei das Massas)". Neste sentido, a Câmara Brasileira da Indústria da Construção [24] demonstrou um procedimento embasado na ISO 15.712/2005 [25] e EN 12.354/2000 [26], para estimativa da isolação acústica de paredes maciças a partir dos resultados obtidos em laboratório, conforme a Equação 7, sendo Rw, o índice de redução sonora, em dB e, M, a massa da parede em $\mathrm{kg} / \mathrm{m}^{2}$.

$$
\mathrm{Rw}=12+5,3 \mathrm{M}^{\frac{1}{3}} \mathrm{~dB}(\mathrm{~A})
$$

Cumpre destacar que a ABNT (2013) [2] não estabeleceu limites para a isolação acústica entre paredes de cômodos de uma mesma unidade. Para a avaliação de fachadas, a presença de janelas e portas sem tratamento acústico podem reduzir substancialmente o isolamento acústico de ruído aéreo na vedação vertical externa (conjunto composto por parede e abertura). Contudo, embasado na ISO 15.712/2005 [25] e EN 12.354/2000 [26], estima-se o nível de redução sonora separadamente da parede cega externa, das esquadrias e calcula-se o isolamento acústico ponderado equivalente (Rw,equiv) conforme a Equação 8 e 9, sendo Rw,equiv o índice de redução sonora ponderado equivalente (em $\mathrm{dB}$ ), o STotal, a área total da parede (área da parte cega + área dos caixilhos, em $\mathrm{m}^{2}$ ), $\mathrm{Si}$, a área de cada componente individual da vedação (alvenaria, janela, porta, em $\mathrm{m}^{2}$ ) e Rwi, o índice de redução sonora ponderado de cada componente (em dB).

$$
\begin{aligned}
& \text { Rw, equiv }=10 \cdot \log \frac{\text { Stotal }}{\sum S i . J i} \\
& \mathrm{Ji}=10^{\frac{- \text { Rwi }}{10}}
\end{aligned}
$$

Segundo a ABNT (2013), a atenuação sonora do sistema de vedação vertical externa deverá possibilitar que a intensidade sonora registrada no interior da construção não ultrapasse o mínimo definido. Para tanto, deverá ser considerada a localização da habitação, ou seja, a classe de ruído do entorno. Essa avaliação se 
restringe apenas a áreas de dormitório. No entanto, a norma define estas classes de forma subjetiva, cabendo ao incorporador a interpretação das condições do entorno para definir a classe da moradia em questão. Isso ressalta a indagação de Cunha et al. (2016) [27], quanto à necessidade de uma metodologia normativa padronizada para identificação da classe de ruído do entorno uma vez que a NBR 15.575/2013 não indica métodos objetivos para definir em qual classe de ruído de entorno uma habitação irá se enquadrar. Assim, o estudo do entorno para a determinação da classe de ruído deve considerar as fontes sonoras mais afastadas, a escolha correta dos pontos e horário de medição, bem como, a implantação do edifício no lote, as construções vizinhas e suas volumetrias além da topografia local. Ademais, simulações acústicas podem permitir o estudo dos diferentes cenários de ruído [27]. Lembro-me que medimos com um decibelímetro e tínhamos que considerar alguns ruídos tipo turbina de avião, e outros níveis de ruído em decibéis nos cálculos de conforto ambiental.

Em caráter complementar, Pierrard e Akkerman (2013) [28] buscou identificar a classe de ruído segundo a norma NBR 10.151 (2000) [29], tendo como base os níveis de pressão sonora equivalentes LAeq incidentes a 2 metros das fachadas das edificações para cada classe. Esses níveis devem ser estimados ou simulados por meio de medições em campo e servirão de referência para a classificação do edifício em função do ruído no entorno. Na Tabela 3 observa-se uma síntese destas informações.

Tabela 3: Níveis de pressão sonora LAeq para cada classe de ruído, conforme a localização da habitação (Pierrard; Akkerman, 2013 [28]; NBR 15.575/2013) [2]).

\begin{tabular}{l|l|l}
\hline CLASSE DE RUÍDO & LOCALIZAÇÃO DA HABITAÇÃO & $\begin{array}{l}\text { NíVEL DE PRESSÃO SONORA } \\
\text { EQUIVALENTE (LAEQ })\end{array}$ \\
\hline I & $\begin{array}{l}\text { Habitação localizada distante de fontes de ruído } \\
\text { intenso de quaisquer naturezas }\end{array}$ & Até $60 \mathrm{dBA}$ \\
\hline II & $\begin{array}{l}\text { Habitação localizada em áreas sujeitas a situações de } \\
\text { ruído não enquadráveis nas classes I e III }\end{array}$ & 60 a $65 \mathrm{dBA}$ \\
\hline & $\begin{array}{l}\text { Habitação sujeita a ruído intenso de meios de trans- } \\
\text { porte e de outras naturezas, desde que conforme a } \\
\text { legislação }\end{array}$ & $65 \mathrm{dBA}$ \\
III &
\end{tabular}

Por outro lado, na impossibilidade de realizar a medição do ruído externo, a Secretaria Nacional de Habitação (SNH, 2015) [30] disponibilizou um roteiro para determinação da classe de ruído por meio da contagem número médio de veículos leves e pesados que circulam, por hora, nas vias lindeiras ao empreendimento em função da velocidade máxima da via conforme Tabela 4. A contagem deverá ser realizada no horário de maior tráfego local e o valor determinado deverá ser a média de, pelo menos, 3 contagens realizadas em dias distintos, no horário que apresentar o pior período de exposição. Este método, no entanto, apresenta limitações, uma vez que outras fontes sonoras importantes tais como ruídos ferroviário, aeroviário ou provenientes de fontes outras fixas, construções do entorno, não são consideradas [27].

Tabela 4: Classe de ruído em função dos veículos na via (SNH, 2015 [30]).

\begin{tabular}{l|l|l|l|l|l|l}
\hline CLASSE DE RUÍDO & \multicolumn{3}{l}{ SÓ LEVE } & \multicolumn{3}{l}{$30 \%$ PESADO } \\
\cline { 2 - 7 } & $40 \mathrm{~km} / \mathrm{h}$ & $60 \mathrm{~km} / \mathrm{h}$ & $100 \mathrm{~km} / \mathrm{h}$ & $40 \mathrm{~km} / \mathrm{h}$ & $60 \mathrm{~km} / \mathrm{h}$ & $100 \mathrm{~km} / \mathrm{h}$ \\
\hline I & 180 & 90 & 20 & 20 & 10 & 07 \\
\hline II & 550 & 280 & 70 & 70 & 40 & 24 \\
\hline III & 1700 & 890 & 220 & 220 & 120 & 75 \\
\hline
\end{tabular}

Para avaliação do isolamento sonoro em vedações horizontais entre unidades habitacionais, Nunes, Zini e Pagnussat (2014) [31] ressaltam que "[...] o desempenho acústico de sistemas de piso é avaliado tanto para o ruído aéreo como para o ruído de impacto". A isolação do som aéreo apresenta melhor desempenho, para os ruídos de impacto, mediante a presença de elementos com maior massa, conforme a Lei das Massas. Assim, quanto mais denso o material, maior a transmissão acústica pelo sistema [24]. Contudo, para vedações horizontais, o comportamento acústico frente ao ruído aéreo ou de impacto apresentam diferenças. Desta forma, as soluções construtivas adotadas nem sempre irão atender simultaneamente aos dois requisitos.

Para atenuar o ruído de impacto, soluções que contemplam o sistema massa-mola-massa se mostram relevantes uma vez que provocam o amortecimento ou isolamento da estrutura, dissipando a vibração e, consequentemente, o som transmitido. Também denominadas de "piso flutuante" caracterizam-se por um sistema 
sanduíche, a partir da junção de dois materiais rígidos e outro resiliente, a "mola". Usualmente, na construção civil, é utilizado o sistema laje/manta de propileno/contrapiso, na qual a laje e o contrapiso fazem a função de massa, por serem pesados, e a manta faz o papel da mola, por ser tratar de material resiliente. O piso laminado, composto por contrapiso/manta resiliente/piso laminado consiste em outro exemplo deste sistema [32].

A literatura noticia estudos acerca do desempenho acústico de diferentes tipos de vedação, seja por meio de medições de campo seja por pesquisas em laboratório. Parâmetros normativos serviram de base para inúmeras investigações, tais como a NBR 15.575, ISO 140/1998 e DIN 4109/1989, entre outras, que constataram situações críticas especialmente no que tange o isolamento sonoro de parede vizinhas reforçando a importância do tratamento acústico na fase inicial de projeto, fato que permite amenizar possíveis transtornos causados pela incidência de ruídos indesejáveis [12, 17, 19, 33-35]. A análise estatística de T-Hotteling (pequenas amostras) indicou que os resultados dos índices de isolamento acústico obtidos in situ e simulados foram similares [34]. Complementarmente, verificou-se que o desempenho em campo tem se igualado ou até superado os valores em laboratório. Neste contexto, critérios diferentes poderiam ser definidos para cada tipologia construtiva, bem como, medições/cálculos complementares para normalizar os resultados das medições de laboratório / campo ou converter os resultados de laboratório para a situação de campo [36]. A incerteza associada ao resultado da medição do isolamento sonoro aéreo e diferença padronizada de nível (DnT) determinada na NBR 15.575/2008 foi estimada por meio da Lei de Propagação de Incertezas (ISO/IEC GUIDE 98) [37], bem como por meio de medições diretas dos níveis de pressão sonora (método clássico) e medições de funções de transferência ou respostas impulsivas [38]. Após tratamento estatístico, os resultados indicaram que as variações dos campos sonoros nos ambientes de teste foram os principais fatores de incerteza. De toda forma, o valor de $2 \mathrm{~dB}$ foi apontado como incerteza de medição aceitável para os valores de desempenho acústico normativo [38].

Ao longo dos anos, constatou-se queda significativa no nível do isolamento sonoro das vedações verticais utilizadas nas moradias brasileiras. A opção tradicionalmente adotada nas residências atuais propicia desempenho inferior em comparação com àquelas do passado e/ou outras opções do mercado [39]. Formulações simplificadas e resultados experimentais prévios, foram direcionados ao desempenho acústico de soluções mais leves e de rápida execução, tais como paneis industrializados, uma vez que a diminuição de sua massa pode realçar deficiências na isolação sonora [40]. Neste contexto, pesquisa experimental para caracterização do isolamento sonoro de alvenaria estrutural buscou ampliar os dados bibliográficos sobre o tema, bem como, contribuir para a consolidação de subsídios para os projetistas [41]. Por outro lado, o emprego da Análise Estatística de Energia (SEA) em simulação numérica de câmaras reverberantes e protótipo direcionado às atividades experimentais se mostrou aplicável para suprir a carência de dados e determinar parâmetros acústicos de um exemplar de vedação composto por tijolos maciços, embora apresente algumas restrições [42]. Em outro caso, a verificação do desempenho térmico e acústico foi possível por meio da simulação da temperatura interna de edifício em Belo Horizonte - MG, utilizando o software ESP-r e, bem como, estimativa do tempo de reverberação, por meio de formulação empírica, na qual demonstrou a adequação dos painéis multicamadas com recheio em material isolante como uma alternativa satisfatória para o sistema de vedação vertical [43].

Diante do reduzido número de informações detalhadas acerca propriedades acústicas de sistemas de vedação, estimou-se os valores do índice de redução sonora ponderado para duas paredes construídas em blocos de gesso maciço $(100 \mathrm{~mm})$. Os requisitos mínimos da norma brasileira de desempenho (40 dB) foram verificados em campo apenas na situação de parede entre unidades habitacionais autônomas, sem dormitório. Em laboratório, por outro lado, considerando os parâmetros da ISO 10.140/2010, tal parede, caso fosse cega, poderia atender aos requisitos normativos (39 dB), desde que fosse localizada entre salas e/ou cozinhas e unidade habitacional e/ou áreas comuns (corredores e escadas) [44]. De forma complementar, ensaios de laboratório realizados por Klippel, Tutikian e Oliveira (2018), conforme parâmetros da ISO 10.140/2010, possibilitaram relacionar a espessura do revestimento de argamassa aplicada em blocos cerâmicos com o desempenho acústico do sistema. Assim, $5 \mathrm{~cm}$ de acréscimo na argamassa possibilitaria um aumento de até $7 \mathrm{~dB}$ no isolamento sonoro entre ambientes [45].

Por fim, a simulação do desempenho acústico pode ser uma ferramenta importante para auxiliar o dimensionamento e a escolha dos elementos construtivos na fase de concepção de projeto. Neste contexto, o programa Hipnos Acústica, se mostrou adequado para simular e verificar o desempenho acústico dos sistemas de vedação vertical externa e interna e horizontal (piso e cobertura), conforme critérios estabelecidos na NBR 15.575/2013 e BS EN 12.354/2000 [46]. De forma complementar, cálculos realizados pelo software Insul para verificação dos critérios da NBR 15.575/2013 indicaram que os sistemas de fachada ventilada com porcelanato e fachada de porcelanato aderido em habitação modelo, típicas do Plano Piloto de Brasília, obtiveram índice semelhante de isolamento sonoro, atingindo o nível mínimo de desempenho normativo. Cumpre 
destacar que a esquadria apresentou impacto significativo no isolamento deste sistema de fachada, uma vez que o aumento da sua área levou a uma redução no índice de isolamento do sistema [47]. O nível de conforto acústico de edifício residencial revestido por blocos cerâmicos, sistema tradicionalmente utilizado no Brasil, foi investigado em um caso paulistano, por meio de medições de isolamento de ruído aéreo, avaliação da privacidade com base na inteligibilidade da fala obtida por meio do software Dirac e, também, por avaliação de um júri. Os resultados indicaram atendimento do desempenho mínimo do sistema de vedação $(\mathrm{DnT}, \mathrm{w}=$ $42 \mathrm{~dB}$ ) para os critérios da NBR 15.575/2008. Contudo, tal sistema não atingiria o limite mínimo (45dB), em alguns países europeus, na África do Sul, no Reino Unido, entre outros, que utilizam o mesmo parâmetro para a avaliação do desempenho acústico. A comparação dos critérios brasileiros com àqueles internacionais realça pontos a serem melhorados na norma, apesar do nível mínimo de conforto acústico já ter sido contemplado [48].

Dados referentes a performance de sistemas construtivos disponibilizados por estudos prévios e/ou fornecedores podem auxiliar o embasamento da escolha projetual dos profissionais do mercado da construção civil. Adicionalmente, simulações podem servir para a análise de diferentes opções construtivas e cenários de entorno. Em determinadas situações e/ou casos mais críticos de geração de ruído, barreiras sonoras podem ser previstas para garantir a viabilidade do empreendimento. Ademais, o teste do desempenho edilício pode motivar ajustes, bem como, servir de referência para empreendimentos futuros além de garantir que as instruções para adequação da edificação foram seguidas e os erros de execução não foram constatados. Neste contexto, o presente trabalho, objetiva analisar o desempenho acústico das escolhas projetuais definidas para uma tipologia habitacional de interesse social, frente aos parâmetros da NBR 15.575/2013.

\section{MATERIAIS E MÉTODOS}

O estudo de caso, objeto deste trabalho, consiste na análise de um projeto de habitação de interesse social. Assim, para o desenvolvimento desta pesquisa as seguintes etapas foram seguidas:

i. Caracterização do local e do objeto de estudo;

ii. Caracterização das condições iniciais e de contorno;

iii. Caracterização do método de análise selecionado;

iv. Avaliação do desempenho térmico e acústico: verificação do atendimento dos sistemas construtivos frente aos parâmetros estabelecidos nas partes III, IV e V da norma NBR 15.575 (2013) no tocante aos sistemas de piso e vedações verticais internas e externas, bem como, horizontais (cobertura);

v. Proposição de ajuste e reavaliação dos resultados obtidos, caso algum item não apresente conformidade normativa.

\subsection{Caracterização do local e do objeto de estudo}

Para o presente estudo optou-se pela escolha de um empreendimento de interesse social na fase de projeto e/ou construção em andamento após a entrada em vigor da NBR 15.575 (2013). Ademais, considerou-se, também, a facilidade de acesso a informação e aos materiais necessários para a realização deste estudo. Desta forma, obteve-se selecionou-se um projeto habitacional do Programa Minha Casa Minha Vida (PMCMV) que demonstrou preencher os requisitos para tal. Após a definição do estudo de caso foi realizada a sua caracterização de modo a permitir a definição das condições de contorno da presente pesquisa.

O empreendimento selecionado para este estudo localiza-se no bairro Parque Xangri-lá, em Contagem - MG, situado próximo à divisa com os municípios de Belo Horizonte ( 50m) e Ribeirão das Neves ( 650m), além de fazer parte da região metropolitana de Belo Horizonte - MG. Por se tratar de região em expansão, não tendo sido plenamente consolidada a sua ocupação (Figura 1), sintetizou-se na Tabela 5, os principais estabelecimentos do entorno de modo a caracterizar a situação hipotética considerada nas análises. Cabe destacar que ocupações futuras poderão alterar, significativamente, as condições do local, podendo repercutir em mudanças para se atingir e/ou manter o desempenho térmico e acústico esperado. Considerou-se um raio de influência variando de 100 a $300 \mathrm{~m}$ do local do empreendimento, que foi destacado em vermelho. Por meio de pesquisa de campo, realizada em diferentes dias da semana e horários, enumerou-se os 5 principais imóveis geradores de ruído no entorno do empreendimento. Em relação à ação do vento, considerando que a direção do vento predominante é leste [49], nesta direção encontra-se uma região desocupada referente a divisa da cidade com o município de Contagem. Desta forma, não foram verificados obstáculos significativos para a dispersão das correntes de vento dominantes no local do empreendimento. De modo geral, as edificações situada no entorno imediato do empreendimento apresentam de 1 a 4 pavimentos e lotes de dimensão média de 12x30m. Cumpre destacar que em Belo Horizonte, a Lei 7166/96 [50] estabelece que apenas empreendi- 
mentos destinados ao uso residencial com mais de 300 unidades estarão sujeitos ao Estudo de Impacto de Vizinhança ou edificações não residenciais de maior porte tais como empreendimentos de uso misto com área construída superior a $20.000,00 \mathrm{~m}^{2}$ ou uso coletivo, com mais $6.000,00 \mathrm{~m}^{2}$ construídos, casas de show ou centro de convenções independente da área utilizada pela atividade, casa de festas e eventos com área utilizada superior a $360,00 \mathrm{~m}^{2}$ ou hipermercados com área utilizada igual ou superior a 5.000,00 $\mathrm{m}^{2}$. Desta forma os imóveis da região não se enquadrariam nesta exigência.

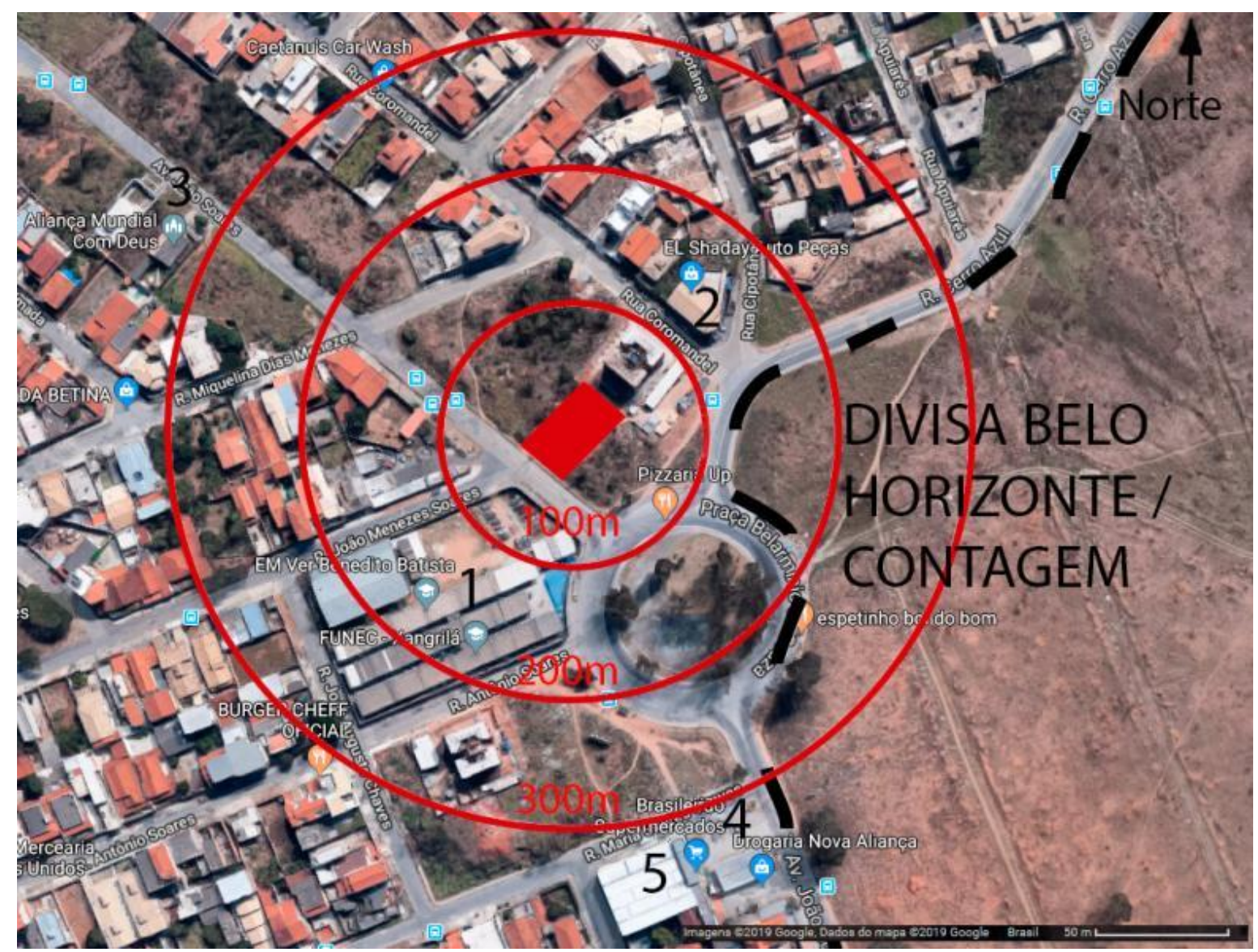

Figura 1: Imagem satélite do entorno do empreendimento (Google Maps [51], modificado pelo autor).

Tabela 5: Caracterização do entorno do empreendimento.

\begin{tabular}{l|l}
\hline TIPO DE IMÓVEL & DISTÁNCIA APROXIMADA \\
\hline $\begin{array}{l}\text { 1. Escola Municipal Vereador Benedito Batis- } \\
\text { ta }\end{array}$ & 50 metros \\
\hline 2. Loja EL Shaday AutoPeças & 70 metros \\
\hline 3. Igreja Aliança Mundial Com Deus & 160 metros \\
\hline 4. Posto de Gasolina Tina & 160 metros \\
\hline 5. Supermercado Brasileirão & 160 metros \\
\hline
\end{tabular}

O local de implantação do edifício insere-se em Zona de Ocupação Restrita 1(ZOR-01), conforme Plano Diretor da Prefeitura Municipal de Contagem [52]. O empreendimento compõe-se por uma torre de quatro pavimentos, sendo quatro unidades no $1^{\circ}, 2^{\circ}$ e $3^{\circ}$ pavimento e dois apartamentos no $4^{\circ}$ pavimento, totalizando quatorze unidades residenciais (Figura 2). No primeiro andar, cada unidade possui $51 \mathrm{~m}^{2}$ de área, ao passo que no $2^{\circ}, 3^{\circ}$ e $4^{\circ}$ pavimento as demais unidades possuem $48 \mathrm{~m}^{2} \mathrm{de}$ área, totalizando $777,06 \mathrm{~m}^{2} \mathrm{de}$ área construída. 


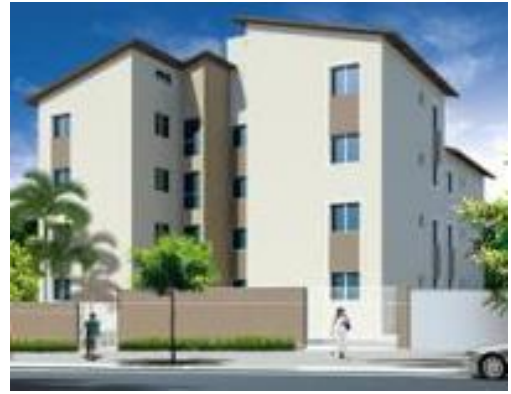

Figura 2: Perspectiva do empreendimento (Arquivo do acervo disponibilizado pela construtora).

O empreendimento enquadra-se na Faixa 3 do PMCMV e, para a sua concepção, considerou-se a natureza social do imóvel, bem como, o baixo custo agregado. Os apartamentos possuem dois quartos, banheiro, sala e cozinha integrada com área de serviços, conforme se observa na Figura 3.

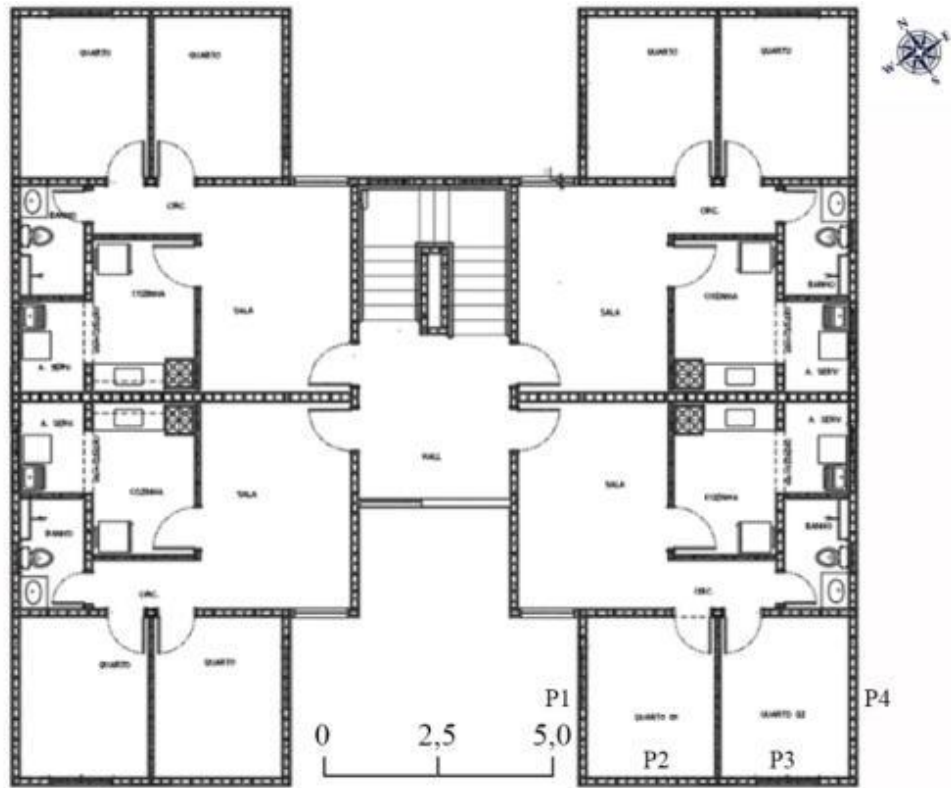

Figura 3: Planta baixa do pavimento tipo (Arquivo do acervo disponibilizado pela construtora).

Conforme consta no caderno de especificações e memorial descritivo da obra, verificou-se algumas premissas relevantes que embasaram a concepção do projeto arquitetônico. Neste contexto, a disposição dos recintos de permanência prolongada (sala e quartos) foi planejada, na medida do possível, de forma a reduzir a interferência sonora provocada por cômodos de unidades vizinhas e por áreas de uso comum. Assim, conforme se observa na Figura 3, os dormitórios foram dispostos na extremidade da habitação ao passo que a sala de estar ficou posicionada de forma adjacente a sala da unidade vizinha e a área de uso comum do edifício (hall). Em razão da metragem do apartamento ser reduzida, as opções de layout para a disposição dos aposentos foram restritas, impossibilitando, assim, o remanejamento da sala de estar e, por esta razão, definiu-se a utilização de blocos cerâmicos mais espessos para essa vedação, buscando aumentar o seu nível isolação sonora.

Na tentativa de reduzir o ruído proveniente dos shafts, os banheiros foram voltados para o lado externo, não apresentando nenhuma instalação hidráulica na parede comum ao quarto, apesar da norma de desempenho considerar na análise de ruídos para estes casos apenas o acionamento destes equipamentos produzidos por apartamentos vizinhos. Quanto ao projeto de instalações elétricas, verificou-se um estudo direcionado de modo a evitar a sobreposição de caixas elétricas instaladas nas alvenarias. O espaçamento das caixas tem como objetivo evitar frestas que podem prejudicar o isolamento acústico previsto. Segundo a Câmara Brasileira da Indústria da Construção - CBIC (2013), pequenas frestas podem reduzir em mais de 30\% a isolação acústica [24]. Por fim, para o projeto de esquadrias foi previsto que após a instalação das janelas, que são parafusadas sobre a estrutura, as folgas existentes deverão ser preenchidas com argamassa, espuma expansiva 
de poliuretano, selantes de cura neutra à base de silicone ou uma combinação destes materiais. Esta medida poderá potencializar o desempenho da vedação e reduzir a propagação de som pela vedação vertical externa.

\subsection{Caracterização das condições iniciais e de contorno}

Neste tópico apresenta-se as condições iniciais e de contorno necessárias para a análise do desempenho termo acústico do estudo de caso, objeto desta pesquisa. Assim, caracterizou-se o enquadramento da localidade no que tange a zona bioclimática (ZB) brasileira, estimou-se a classe de ruído em questão, bem como, especificou-se os sistemas construtivos considerados no projeto em análise.

A apuração da ZB condiciona as diretrizes técnico-construtivas recomendadas para determinada localidade. Para a definição da ZB em que se insere o estudo de caso, adotou-se o programa ZBBR versão 1.1 [53] em complemento a classificação bioclimática dos municípios brasileiros apresentada na NBR 15220-3 /2008 [54]. Assim, considerando que o empreendimento está localizado em Contagem - MG, a zona bioclimática em que se encontra a edificação em questão é a ZB 2, conforme demonstrado na Figura 4. Ademais, verifica-se os dados geográficos do local, bem como, recomendações construtivas e estratégias sazonais para adequação do edifício ao clima de Contagem. Cumpre destacar que o empreendimento se encontra em uma região muito próxima a divisa com a cidade de Belo Horizonte - MG, que está localizada na ZB 3 [54], fato que ressalta a limitação do zoneamento proposto na norma 15.220/2008 uma vez que regiões vizinhas, a poucos metros de distância, se encontram-se em zonas diferentes.

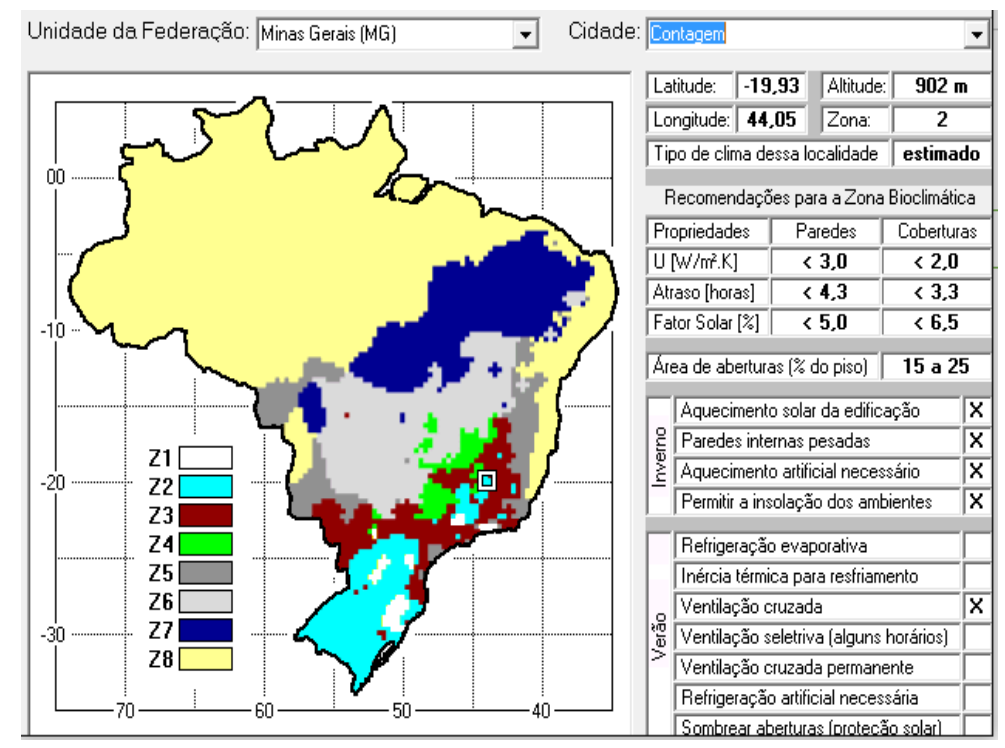

Figura 4: Classificação Bioclimática do Município de Contagem (ZBBR [53]).

No presente estudo, a determinação da classe de ruído do entorno foi realizada de forma simplificada. Tal procedimento possibilita ao projetista uma análise prévia mais acessível e veloz, sem dispêndios adicionais para medições in loco. Assim, utilizou-se como referência a base de dados municipal sobre as vias [55]. Conforme se verifica na Figura 5, o estudo de caso objeto desta pesquisa se localiza em uma via local, representada pelo arruamento, próxima à uma via coletora principal, destacada em azul. 


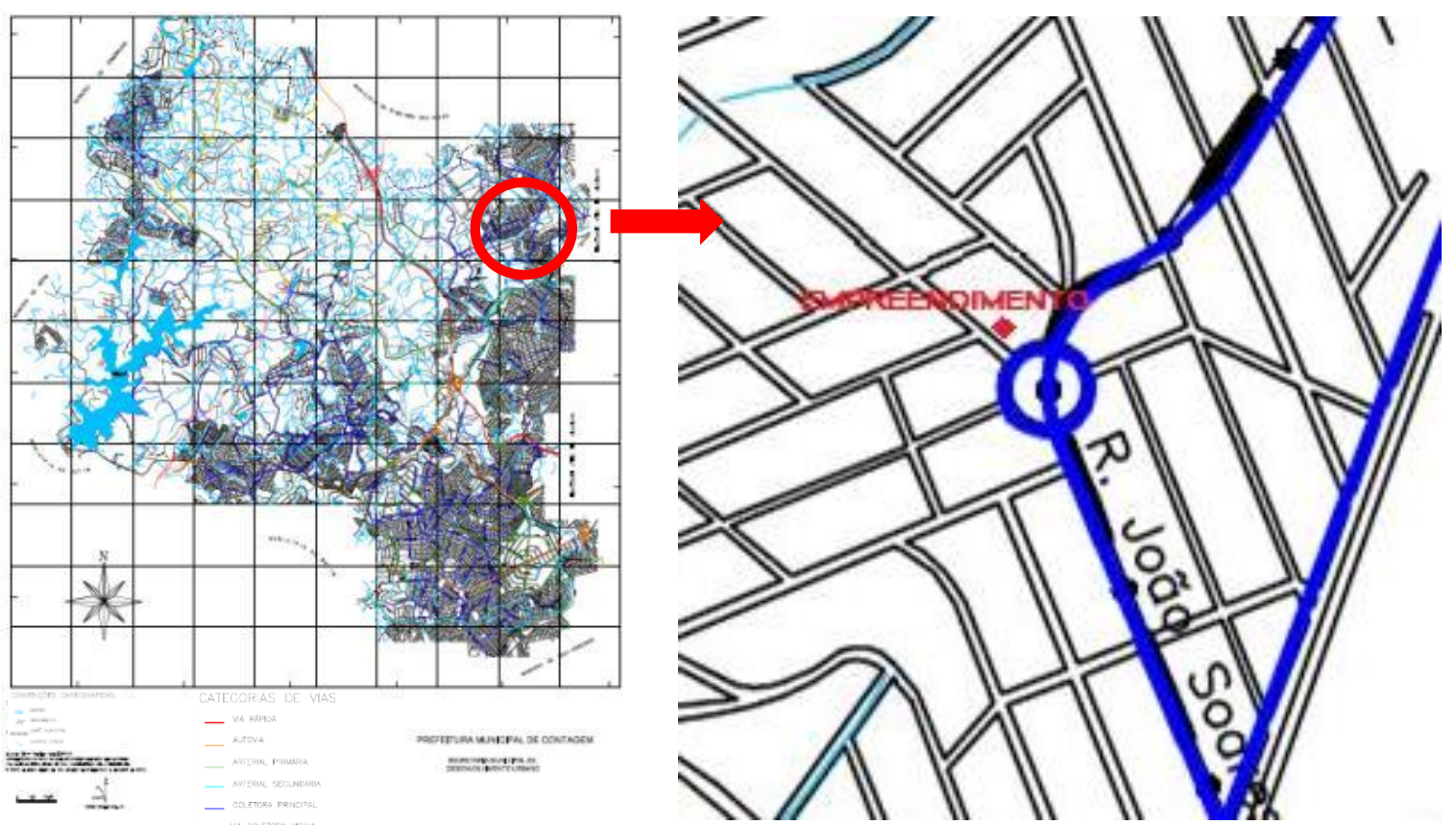

Figura 5: Mapa de hierarquização do sistema viário (Lei Complementar $N^{\circ}$ 082/2010 [55]).

Na ausência de um referencial municipal específico adotou-se os valores máximos determinados pela Lei Municipal Ambiental no 4253/1985 [56] que rege o controle da poluição sonora em Belo Horizonte, uma vez que a cidade de Contagem - MG faz parte da região metropolitana de Belo Horizonte - MG. O Decreto Municipal no 5893/1988 [57], que regulamenta a lei citada, estabelece em seu artigo 13 que: “[...] independente do ruído de fundo, o nível de som proveniente da fonte poluidora, medido dentro dos limites reais da propriedade onde se dá o suposto incômodo, não poderá exceder os níveis fixados na Tabela [...]”. Os níveis de som máximos referenciados neste decreto podem ser observados na Tabela 6.

Tabela 6: Níveis máximos de som em dB(A) (Decreto 5.893/1988 [57]).

\begin{tabular}{|c|c|c|c|c|}
\hline \multicolumn{2}{|c|}{$\begin{array}{l}\text { LOCALIZAÇÃO DA PROPRIEDADE SUJEITA AO } \\
\text { SUPOSTO INCOOMODO }\end{array}$} & \multicolumn{3}{|l|}{ HORÁRIOS } \\
\hline $\begin{array}{l}\text { Zona de Usos e Ocupação } \\
\text { do Solo }\end{array}$ & $\begin{array}{l}\text { Classificação das } \\
\text { Vias }\end{array}$ & \begin{tabular}{ll|} 
Diurno \\
$(07 h 00$ \\
$19 h 00)$
\end{tabular} & \begin{tabular}{|l|} 
Vespertino $(19 \mathrm{~h} 00$ \\
às $22 \mathrm{~h} 00)$
\end{tabular} & $\begin{array}{l}\text { Noturno } \\
(22 \mathrm{~h} 00 \quad \text { às } \\
07 \mathrm{~h} 00)\end{array}$ \\
\hline $\begin{array}{l}\text { Zona de Preservação Am- } \\
\text { biental (ZPAM), Zona de } \\
\text { Proteção } 1 \text { e } 2 \text { (ZP1 e } \\
\text { ZP2) }\end{array}$ & Todas as vias & $55 \mathrm{~dB}(\mathrm{~A})$ & $50 \mathrm{~dB}(\mathrm{~A})$ & $45 \mathrm{~dB}(\mathrm{~A})$ \\
\hline & Local & $60 \mathrm{~dB}(\mathrm{~A})$ & $55 \mathrm{~dB}(\mathrm{~A})$ & $50 \mathrm{~dB}(\mathrm{~A})$ \\
\hline & Coletora & $65 \mathrm{~dB}(\mathrm{~A})$ & $60 \mathrm{~dB}(\mathrm{~A})$ & $55 \mathrm{~dB}(\mathrm{~A})$ \\
\hline Demais Zonas de Uso & $\begin{array}{|ll|}\text { Ligação } & \text { Regional e } \\
\text { Arterial } & \\
\end{array}$ & $70 \mathrm{~dB}(\mathrm{~A})$ & $60 \mathrm{~dB}(\mathrm{~A})$ & $55 \mathrm{~dB}(\mathrm{~A})$ \\
\hline
\end{tabular}

Assim, cumpre destacar que a Lei Municipal do Meio Ambiente 3789/2003 de Contagem - MG [58] não descrimina parâmetros quantitativos para controle das fontes de poluição sonora. Ademais, o empreendimento objeto deste estudo de caso localiza-se junto a divisa com o município de Belo Horizonte - MG. Por estas razões, utilizou-se a Tabela 6 como referência para a determinação do valor máximo permitido de ruído no local a fim não ocasionar um suposto incômodo ao morador da região. Para a determinação dos parâmetros de classificação das Zonas de Uso e Ocupação do Solo e do Horário que será considerado na análise, foram adotados os critérios mais críticos da Tabela 6, que são "Demais Zonas de Uso" e o período "Diurno". Tal pressuposto fundamenta-se no fato de que o empreendimento estudado se localiza em uma via local muito próxima outra coletora, conforme verifica-se na Figura 5. Desta forma, para efeito da determinação da classe de ruído, considerou-se que o empreendimento em estudo se encontra em uma via coletora, sendo, neste caso, $65 \mathrm{~dB}$, o valor máximo do nível sonoro permitido em lei. Portanto, conforme Pierrard e Akkerman (2015) [28] o nível de ruído do entorno da edificação pode ser qualificado como Classe II. Esta 
categorização se faz necessária para a avaliação dos limites estabelecidos na NBR 15.575/2013.

Para a análise do desempenho termo acústico do estudo de caso considerou-se como elemento uma parte constituinte do sistema construtivo (parede/piso, etc.) composto pela união de um ou mais componentes. Desta forma, foram consideradas as paredes externas, o sistema de laje dos quartos, a parede de divisa entre unidades da sala e o conjunto de portas e paredes do hall. Para todos os ambientes considerou-se o pé direito de $2,60 \mathrm{~m}$. Precisa de um corte ou das paredes (projeto de alvenaria estrutural) para que alguém que queira conferir se seus resultados estão certos, possa ter acesso as mesmas informações, a descrições textuais ganham mais sentido quando acompanhadas de plantas, croquis, detalhamentos arquitetônicos.

Quanto à análise do desempenho térmico da vedação vertical foram consideradas as paredes externas dos quartos e salas (ambientes de permanência prolongada). Os elementos de cobertura e de piso foram descriminados na Tabela 7, que correlacionou todos os elementos com as respectivas análises (térmica e/ou acústica) que deverão ser realizadas neste estudo.

Tabela 7: Determinação e caracterização dos sistemas construtivos.

\begin{tabular}{|c|c|c|c|}
\hline SISTEMA & ELEMENTO & $\begin{array}{l}\text { ANÁLISE A SER } \\
\text { REALIZADA }\end{array}$ & COMPONENTES \\
\hline \multirow[t]{2}{*}{ 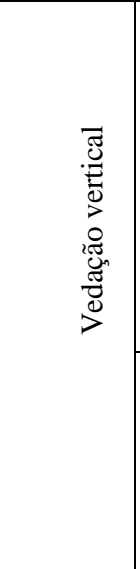 } & Paredes externas & Térmica e acústica & $\begin{array}{l}\text { - Alvenaria de blocos cerâmicos estruturais com dimensões } \\
\text { de 140mm x 190mm x } 390 \text { mm e furos na vertical; } \\
\text { - Revestimento interno de gesso com espessura de } 8 \mathrm{~mm} \text {; } \\
\text { - Revestimento externo de argamassa de cimento e areia, } \\
\text { com espessura de } 16 \mathrm{~mm} \text {; } \\
\text {-Janelas na modalidade de kit pronto para colocação da } \\
\text { linha Beluno, sendo duas folhas de correr em alumínio, de } \\
\text { 1,20x1,20 m cada. }\end{array}$ \\
\hline & $\begin{array}{l}\text { Parede entre unidades } \\
\text { habitacionais autôno- } \\
\text { mas (parede de gemi- } \\
\text { nação), nas situações } \\
\text { em que não haja dor- } \\
\text { mitório }\end{array}$ & Acústica & $\begin{array}{l}\text { - Alvenaria de blocos cerâmicos estruturais com dimensões } \\
\text { de 190mm x 190mm x } 390 \mathrm{~mm} \text { e furos na vertical; } \\
\text { - Revestimento interno de gesso com espessura de } 8 \mathrm{~mm} \text { em } \\
\text { ambas as faces. }\end{array}$ \\
\hline
\end{tabular}

Tabela 8: Determinação e caracterização dos sistemas construtivos (Continuação).

\begin{tabular}{|c|c|c|c|}
\hline SISTEMA & ELEMENTO & $\begin{array}{l}\text { ANÁLISE A SER } \\
\text { REALIZADA }\end{array}$ & COMPONENTES \\
\hline 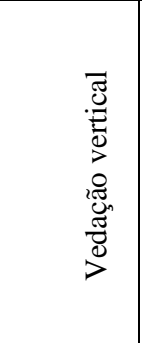 & 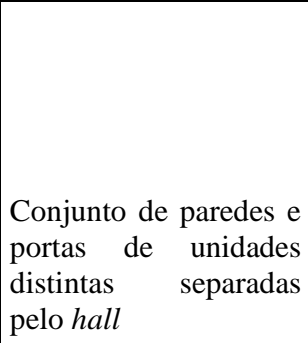 & Acústica & $\begin{array}{l}\text { - Alvenarias de blocos cerâmicos estruturais, com dimen- } \\
\text { sões de } 140 \mathrm{~mm} \text { x } 190 \mathrm{~mm} \text { x } 390 \mathrm{~mm} \text { e furos na vertical; } \\
\text { - Câmera de ar do hall/corredor que é delimitado pelos } \\
\text { conjuntos de paredes e portas das unidades distintas, dis- } \\
\text { tantes em } 3 \mathrm{~m} \text {; } \\
\text { - Revestimento interno de gesso com espessura de } 8 \mathrm{~mm} \text { em } \\
\text { ambas as faces da alvenaria; } \\
\text { - Porta pronta de madeira, } 80 \times 210 \mathrm{~cm} \text {. }\end{array}$ \\
\hline$\stackrel{0}{0}$ & $\begin{array}{l}\text { Piso de separação de } \\
\text { unidades habitacionais } \\
\text { autônomas de áreas em } \\
\text { que um dos recintos } \\
\text { seja dormitório }\end{array}$ & Acústica & $\begin{array}{l}\text { - Concreto armado sobre a laje pré-moldada, totalizando } \\
\text { em } 120 \mathrm{~mm} \text { de espessura de laje; } \\
\text { - Contrapiso de argamassa convencional de } 30 \mathrm{~mm} \text { espes- } \\
\text { sura; } \\
\text { - Piso vinílico em manta }(1,2 \mathrm{~mm}) \text {. }\end{array}$ \\
\hline 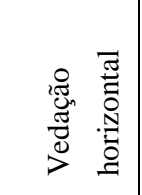 & Cobertura & Térmica e acústica & $\begin{array}{l}\text { - Concreto armado sobre a laje pré-moldada, totalizando } \\
\text { em } 120 \mathrm{~mm} \text { de espessura de laje; } \\
\text { - Telha cerâmica (espessura de 1,0cm) fixada em estrutura } \\
\text { de madeira. }\end{array}$ \\
\hline
\end{tabular}




\subsection{Caracterização do método de análise selecionado}

$\mathrm{Na}$ análise do desempenho térmico utilizou-se as formulações apresentadas na NBR 15220-2/2008 [10] para estimar o desempenho da envoltória e verificar o atendimento aos limites estabelecidos pela NBR 15.575/2013. Desta forma, foram calculados os valores de transmitância térmica (U) e capacidade térmica (CT) dos sistemas de vedação horizontal e vertical externos.

Para avaliação do desempenho acústico a NBR 15.575/2013 estabelece que para o sistema de pisos se faz necessário avaliar o som resultante de ruídos de impacto (caminhamento, queda de objetos e outros) entre unidades habitacionais (UH). Para a análise dos níveis de ruído permitidos na habitação, considerou-se, inicialmente o piso que separa unidades habitacionais autônomas (UHA) de áreas em que um dos recintos seja dormitório. A unidade habitacional (UH) de referência adotada na análise do desempenho acústico, foi o apartamento 202, localizado em andar intermediário, a fim de verificar o sistema de piso em relação à unidade de baixo. Neste contexto, foram verificados os quartos 01 e 02 (Figura 3) que apresentam separação por elemento de piso dos respectivos quartos do apartamento 102, localizado no nível inferior e, com as mesmas dimensões em planta em relação a esta unidade.

Por outro lado, para a análise do desempenho acústico, a adoção do software Projetus [59] permitiu verificar o desempenho acústico estabelecido na NBR 15.575/2013 a partir da determinação dos seguintes parâmetros: índice de desempenho acústico de fachadas, de paredes internas, de piso ao ruído aéreo / de impacto e tempo de reverberação em ambientes. Os procedimentos utilizados para a estimativa da isolação acústica dos elementos pelo programa seguem definições da norma EN 12.354/2000 [26]. Para análise do desempenho acústico ao som aéreo de paredes e pisos internos, o software considera a interferência dos elementos adjacentes àquele principal, objeto de avaliação. Assim, verificaram-se todas as vedações em contato com o elemento analisado e, também, definiu-se os tipos de vinculações existentes nos encontros entre tais elementos. Posteriormente, determinou-se, analiticamente, o valor do desempenho acústico do elemento em questão.

Cumpre destacar que, em virtude de limitação do software, as esquadrias, neste caso portas, não foram consideradas no cálculo de atenuação sonora entre o conjunto de paredes e portas de unidades distintas separadas pelo hall e pelas portas de entrada do apartamento. Tal fato poderá gerar distinção dos valores encontrados em comparação com o desempenho real destes elementos. Por outro lado, a interferência das esquadrias externas foi considerada nos sistemas de vedações verticais para a análise acústica das fachadas. Para dimensionamento dos elementos de parede e piso foi utilizado o banco de dados do software, no qual os materiais foram selecionados, juntamente com a indicação da sua espessura, em metros. Com base nessas informações, o programa calculou a massa superficial, em kg/m² e, a partir disto, dimensionou o $\mathrm{Rw}$, em $\mathrm{dB}$, e o L'nT,w (no caso das lajes), em dB, do conjunto.

Vale ressaltar que o elemento de cobertura especificado para a análise acústica não contempla a estrutura de madeira e telhamento, exceto para avaliação sonora do sistema de cobertura. A supressão destes elementos a título de simplificação do cálculo do índice de redução sonora ao ruído aéreo não interfere na análise térmica, uma vez que essa adaptação não alterou a especificação original do sistema.

No desenvolvimento deste estudo também foram utilizados os métodos de cálculo previstos normas ISO 15.712/2005 [25] e EN 12.354/2000 [26] que apresentam procedimentos para se estimar a isolação acústica a partir dos resultados obtidos em laboratório. Desta forma, estimou-se a isolação acústica das paredes cegas do apartamento que fazem divisa com outra unidade habitacional e das paredes externas do dormitório. A abordagem dos elementos sujeitos à análise acústica contemplou àqueles principais e complementares para as análises de som aéreo em paredes e pisos internos. Por fim, os resultados estimados pelas equações foram contrastados com os resultados obtidos pela simulação acústica. A Tabela 9 sintetiza os métodos de verificação aplicados para a avaliação do desempenho acústico deste trabalho.

Tabela 9: Métodos utilizados para verificação dos parâmetros acústicos.

\begin{tabular}{l|l|l}
\hline SISTEMA CONSTRUTIVO & CRITÉRIO & MÉTODO PARA ANÁLISE ACÚSTICA \\
\hline $\begin{array}{l}\text { Piso de separação entre unida- } \\
\text { des habitacionais autônomas }\end{array}$ & $\begin{array}{l}\text { Isolamento ao } \\
\text { ruído de im- } \\
\text { (UHA) em pavimentos distintos }\end{array}$ & $\begin{array}{l}\text { Simulação por meio software Projetus para dimensionamento do } \\
\text { nível de pressão sonora de impacto em divisórias de piso, } \\
\text { L’nT,w, em dB. }\end{array}$ \\
\hline $\begin{array}{l}\text { Piso de separação entre UHA e } \\
\text { áreas em que um dos recintos } \\
\text { seja dormitório }\end{array}$ & $\begin{array}{l}\text { Isolamento ao } \\
\text { som aéreo }\end{array}$ & $\begin{array}{l}\text { Simulação por meio software Projetus para dimensionamento do } \\
\text { índice de desempenho acústico do piso, DnT,w, em dB. }\end{array}$ \\
\hline
\end{tabular}




\begin{tabular}{|c|c|c|}
\hline $\begin{array}{l}\text { Vedação vertical externa de } \\
\text { dormitório }\end{array}$ & $\begin{array}{l}\text { Isolamento ao } \\
\text { som aéreo }\end{array}$ & $\begin{array}{l}\text { 1) Simulação por meio software Projetus para dimensionamento } \\
\text { do índice de desempenho acústico de fachadas, D2m,nT,w, em } \\
\text { dB, das vedações externas; } \\
\text { 2) Cálculo do isolamento acústico ponderado equivalente } \\
\text { (Rw,equiv) das paredes externas por meio equação } 8 \text { e } 9 \text { apresen- } \\
\text { tada no item 1.2; } \\
\text { 3) Comparação dos resultados obtidos nos itens 1) e 2) e adoção } \\
\text { dos valores mais críticos para a avaliação do desempenho. }\end{array}$ \\
\hline $\begin{array}{l}\text { Vedação vertical entre UHA } \\
\text { (parede de geminação) nas situ- } \\
\text { ações nas quais não haja dormi- } \\
\text { tório }\end{array}$ & $\begin{array}{l}\text { Isolamento ao } \\
\text { som aéreo }\end{array}$ & $\begin{array}{l}\text { 1) Simulação por meio software Projetus para dimensionamento } \\
\text { do índice de desempenho acústico de uma parede vertical divisó- } \\
\text { ria, DnT,w, em dB; } \\
\text { 2) Cálculo do isolamento acústico ( } \mathrm{Rw} \text { ) das paredes divisórias } \\
\text { maciças por meio equação } 7 \text {, conforme demonstrado no item } 1.2 \text {, } \\
\text { que leva em consideração a massa da parede em } \mathrm{kg} / \mathrm{m}^{2} \text {; }\end{array}$ \\
\hline $\begin{array}{l}\text { Vedação vertical entre UHA } \\
\text { (parede de geminação) nas situ- } \\
\text { ações nas quais não haja dormi- } \\
\text { tório }\end{array}$ & $\begin{array}{l}\text { Isolamento ao } \\
\text { som aéreo }\end{array}$ & $\begin{array}{l}\text { 3) Comparação dos resultados obtidos nos itens 1) e 2) e adoção } \\
\text { dos valores mais críticos. }\end{array}$ \\
\hline $\begin{array}{l}\text { Conjunto de paredes e portas de } \\
\text { unidades distintas separadas } \\
\text { pelo hall }\end{array}$ & $\begin{array}{l}\text { Isolamento ao } \\
\text { som aéreo }\end{array}$ & $\begin{array}{l}\text { Simulação por meio software Projetus para dimensionamento do } \\
\text { índice de desempenho acústico do conjunto, DnT,w, em dB. }\end{array}$ \\
\hline Sistema de cobertura & $\begin{array}{l}\text { Isolamento ao } \\
\text { som aéreo }\end{array}$ & $\begin{array}{l}\text { Cálculo do isolamento acústico (Rw) do sistema de cobertura por } \\
\text { meio do software Projetus. }\end{array}$ \\
\hline
\end{tabular}

Destaca-se que cobertura foi considerada como um item a parte possibilitando a sua avaliação como um todo. Devido as particularidades do estudo de caso, cumpre destacar que o isolamento ao ruído de impacto não contemplou o sistema de cobertura enquanto o isolamento ao som aéreo não foi aplicado para as paredes cegas entre UH e dormitório e/ou salas e cozinhas, associadas a áreas comuns de trânsito eventual, como corredores e escadas ou vinculadas as áreas comuns com permanência de pessoas.

\section{RESULTADOS}

Nesta seção foram apresentados os resultados obtidos para a análise do desempenho térmico e acústico da habitação multifamiliar. Destaca-se que todos os ambientes as UH apresentam a área mínima para iluminação e ventilação conforme estabelece o Código de Obras do Município de Contagem.

\subsection{Desempenho térmico}

Para a zona bioclimática 2 (ZB2), área em que se localiza o estudo de caso, a NBR 15.575/2013 estabelece apenas limites mínimos para a transmitância térmica $\left(\mathrm{U} \leq 2,5 \mathrm{~W} / \mathrm{m}^{2} . \mathrm{K}\right)$ e capacidade térmica $(\mathrm{CT} \geq 130$ $\left.\mathrm{kJ} / \mathrm{m}^{2} . \mathrm{K}\right)$ das paredes externas $\left(\mathrm{U} \leq 2,5 \mathrm{~W} / \mathrm{m}^{2} . \mathrm{K}\right)$, independentemente do valor da absortância à radiação solar $(\alpha)$ incidente na superfície vertical externa. Por outro lado, para a cobertura, a referida norma apresenta critérios mínimos $\left(\mathrm{U} \leq 2,3 \mathrm{~W} / \mathrm{m}^{2} \cdot \mathrm{K}\right)$, intermediários $\left(\mathrm{U} \leq 1,5 \mathrm{~W} / \mathrm{m}^{2} \cdot \mathrm{K}\right)$ e superiores $\left(\mathrm{U} \leq 1,0 \mathrm{~W} / \mathrm{m}^{2} \cdot \mathrm{K}\right)$, sem exigência para CT e $\alpha$.

O sistema de vedação vertical do presente estudo é composto por alvenaria estrutural de bloco cerâmico vazado $(140 \mathrm{~mm}$ x $190 \mathrm{~mm}$ x $390 \mathrm{~mm}$ ) com revestimento interno de argamassa (emboço=10mm) e gesso corrido $(8 \mathrm{~mm})$ além de revestimento externo de argamassa (reboco $=16 \mathrm{~mm})$. As dimensões dos vazados e as espessuras das paredes internas do bloco cerâmico foram medidas em uma amostra do mesmo tipo de bloco que foi fornecido à construtora. Assim, considerando que no banco de dados do ProjetEEE [8] não foi encontrado um sistema construtivo semelhante ao estudo de caso estimou-se os valores de U e CT com base no método apresentado na NBR 15220-2/2008. Na Figura 6 exemplificou-se as camadas que compõem a veda- 
ção vertical externa e, na Tabela 9, detalhou-se a composição de cada uma destas seções. Desta forma, considerando os sete tipos de seção não homogênea (variando de A a G), verificou-se não conformidade deste sistema, sendo $\mathrm{U}=2,49 \mathrm{~W} / \mathrm{m}^{2} . \mathrm{K}$ e $\mathrm{CT}=110 \mathrm{~kJ} / \mathrm{m}^{2} . \mathrm{K}$. Em suma, apesar do limite de $\mathrm{U}$ atender à exigência normativa, o valor de CT apresentou-se $20 \mathrm{~kJ} / \mathrm{m}^{2}$.K aquém da referência não possibilitando, portanto, o cumprimento da exigência mínima para o método simplificado da NBR 15.575/2013 de análise do desempenho térmico da envoltória.

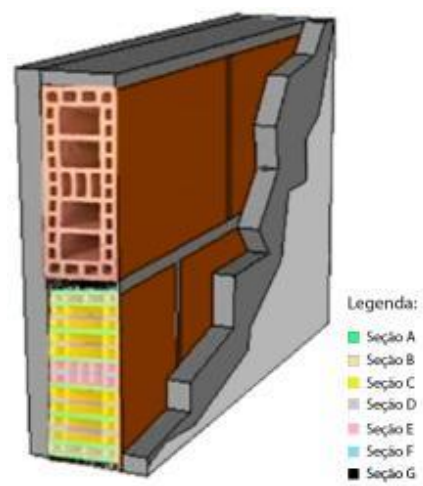

Figura 6: Esquema das seções constituintes do sistema de vedação vertical.

Tabela 10: Materiais constituintes das seções do sistema de vedação vertical.

\begin{tabular}{|c|c|}
\hline SEÇÃO & MATERIAIS CONSTITUINTES \\
\hline A & Gesso liso $(8 \mathrm{~mm})$, emboço interno $(10 \mathrm{~mm})$, cerâmica $(140 \mathrm{~mm})$, reboco externo $(16 \mathrm{~mm})$ \\
\hline B & $\begin{array}{l}\text { Gesso liso }(8 \mathrm{~mm}) \text {, emboço interno }(10 \mathrm{~mm}) \text {, cerâmica }(10 \mathrm{~mm}) \text {, câmara de ar não ventilada }(20 \mathrm{~mm}) \text {, cerâ- } \\
\text { mica }(10 \mathrm{~mm}) \text {, câmara de ar não ventilada }(25 \mathrm{~mm}) \text {, cerâmica }(10 \mathrm{~mm}) \text {, câmara de ar não ventilada }(25 \mathrm{~mm}) \text {, } \\
\text { cerâmica }(10 \mathrm{~mm}) \text {, câmara de ar não ventilada }(20 \mathrm{~mm}) \text {, cerâmica }(10 \mathrm{~mm}) \text {, reboco externo }(16 \mathrm{~mm})\end{array}$ \\
\hline $\mathrm{C}$ & $\begin{array}{l}\text { Gesso liso }(8 \mathrm{~mm}) \text {, emboço interno }(10 \mathrm{~mm}) \text {, cerâmica }(10 \mathrm{~mm}) \text {, câmara de ar não ventilada }(12,5 \mathrm{~mm}) \text {, ce- } \\
\text { râmica }(10 \mathrm{~mm}) \text {, câmara de ar não ventilada }(75 \mathrm{~mm}) \text {, cerâmica }(10 \mathrm{~mm}) \text {, câmara de ar não ventilada } \\
(12,5 \mathrm{~mm}) \text {, cerâmica }(1 \mathrm{~mm}) \text {, reboco externo }(16 \mathrm{~mm})\end{array}$ \\
\hline $\mathrm{D}$ & $\begin{array}{l}\text { Gesso liso }(8 \mathrm{~mm}) \text {, emboço interno }(10 \mathrm{~mm}) \text {, cerâmica }(32,5 \mathrm{~mm}) \text {, câmara de ar não ventilada }(75 \mathrm{~mm}) \text {, ce- } \\
\text { râmica }(32,5 \mathrm{~mm}) \text {, reboco externo }(16 \mathrm{~mm})\end{array}$ \\
\hline $\mathrm{E}$ & $\begin{array}{l}\text { Gesso liso }(8 \mathrm{~mm}) \text {, emboço interno }(10 \mathrm{~mm}) \text {, cerâmica }(10 \mathrm{~mm}) \text {, câmara de ar não ventilada }(10 \mathrm{~mm}) \text {, cerâ- } \\
\text { mica }(10 \mathrm{~mm}) \text {, câmara de ar não ventilada }(20 \mathrm{~mm}) \text {, cerâmica }(10 \mathrm{~mm}) \text {, câmara de ar não ventilada }(20 \mathrm{~mm}) \text {, } \\
\text { cerâmica }(10 \mathrm{~mm}) \text {, câmara de ar não ventilada }(20 \mathrm{~mm}) \text {, cerâmica }(10 \mathrm{~mm}) \text {, câmara de ar não ventilada } \\
(10 \mathrm{~mm}) \text {, cerâmica }(10 \mathrm{~mm}) \text {, reboco externo }(16 \mathrm{~mm})\end{array}$ \\
\hline $\mathrm{F}$ & $\begin{array}{l}\text { Gesso liso }(8 \mathrm{~mm}) \text {, emboço interno }(10 \mathrm{~mm}) \text {, cerâmica }(30 \mathrm{~mm}) \text {, câmara de ar não ventilada }(20 \mathrm{~mm}) \text {, cerâ- } \\
\text { mica }(10 \mathrm{~mm}) \text {, câmara de ar não ventilada }(20 \mathrm{~mm}) \text {, cerâmica }(10 \mathrm{~mm}) \text {, câmara de ar não ventilada }(20 \mathrm{~mm}) \text {, } \\
\text { cerâmica }(30 \mathrm{~mm}) \text {, reboco externo }(16 \mathrm{~mm})\end{array}$ \\
\hline $\mathrm{G}$ & $\begin{array}{l}\text { Gesso liso }(8 \mathrm{~mm}) \text {, emboço interno }(10 \mathrm{~mm}) \text {, argamassa de assentamento dos blocos }(140 \mathrm{~mm}) \text {, reboco ex- } \\
\text { terno }(16 \mathrm{~mm})\end{array}$ \\
\hline
\end{tabular}

No que tange ao sistema de cobertura, para o seu dimensionamento foi utilizado a banco de dados do ProjetEEE [8] que apresentada uma opção semelhante ao sistema de vedação horizontal adotado no estudo de caso. Neste contexto, a vedação vertical é composta por concreto armado sobre a laje pré-moldada $3 \mathrm{~cm}$ mais $9 \mathrm{~cm}$ de capeamento de concreto, totalizando $120 \mathrm{~mm}$ de espessura de laje, câmara de ar $(>5 \mathrm{~cm})$, estrutura de madeira e telha cerâmica $(1 \mathrm{~cm})$. Desta forma, constatou-se que este sistema atendeu ao desempenho térmico normativo mínimo exigido $\left(\mathrm{U}=1,52 \mathrm{~W} / \mathrm{m}^{2} . \mathrm{K}\right)$ para a $\mathrm{ZB} 2$.

Em síntese, a envoltória da edificação está em desconformidade com a NBR 15.575/2013 considerando que o parâmetro de CT estabelecido para o sistema de vedação vertical não atingiu o limite mínimo. Tal item deverá, portanto, ser ajustado para permitir o atendimento das exigências normativas para o quesito térmico.

\subsection{Desempenho acústico}

A partir de informações prévias cadastradas no banco de dados do Projetus [59] estimou-se a composição dos elementos principais a serem analisados no quesito desempenho acústico deste estudo. Além disto, foram geradas como saídas a massa superficial $\left(\mathrm{kg} / \mathrm{m}^{2}\right), \mathrm{Rw}(\mathrm{dB})$ e L’nT,w $(\mathrm{dB})$, conforme se observa na Tabela 11. 
Tabela 11: Composição dos elementos principais a serem considerados na análise acústica.

\begin{tabular}{l|c|c|c}
\hline \multicolumn{1}{c|}{ Elemento } & Massa superficial (kg/m²) & $\mathbf{R w}(\mathbf{d B})$ & \multicolumn{1}{c}{ '’nT,w (dB) } \\
\hline Sistema de cobertura & 300,00 & 50,90 & Não se aplica. \\
\hline Parede externa & 161,80 & 40,80 & Não se aplica. \\
\hline $\begin{array}{l}\text { Parede entre UHA (parede de geminação), nas situações } \\
\text { nas quais não haja ambiente dormitório }\end{array}$ & 166,15 & 41,30 & Não se aplica. \\
\hline $\begin{array}{l}\text { Conjunto de paredes e portas de unidades distintas sepa- } \\
\text { radas pelo hall }\end{array}$ & 257,40 & 48,40 & Não se aplica. \\
\hline $\begin{array}{l}\text { Sistema de piso separando UHA de áreas em que um dos } \\
\text { recintos seja dormitório }\end{array}$ & 354,32 & 53,60 & 74,80 \\
\hline $\begin{array}{l}\text { Parede divisória entre os quatros 01 e 02 } \\
\text { Parede divisória entre quarto e a sala e entre sala e área } \\
\text { comum (hall corredor) }\end{array}$ & 91,00 & 31,50 & Não se aplica. \\
\hline Parede divisória entre sala e cozinha & 127,20 & 36,90 & Não se aplica. \\
\hline
\end{tabular}

Para o desempenho acústico normativo mínimo referente ao sistema de cobertura, a avaliação do seu isolamento acústico devido a sons aéreos deverá atingir o valor maior ou igual a $25 \mathrm{~dB}$ para a $\mathrm{D} 2 \mathrm{~m}, \mathrm{nT}$, w, de acordo com a localização do empreendimento. $\mathrm{O}$ valor de referência $\mathrm{Rw}$ adotado para as fachadas de $30 \mathrm{~dB}$ foi utilizado, como base para análise do sistema de cobertura, na ausência de referencial específico. Conforme dados apresentados na Tabela 11, verifica-se que o sistema de cobertura composto pelo sistema de piso formado por laje maciça de concreto armado $(120 \mathrm{~mm})$, contrapiso de argamassa convencional $(30 \mathrm{~mm}) \mathrm{e}$ piso vinílico em manta $(1,2 \mathrm{~mm})$ atendeu ao desempenho mínimo de atenuação sonora exigido pela NBR 15.575/2013, para a classe de ruído definida para o estudo de caso. Como não há previsão de áreas de uso coletivo sobre unidades habitacionais autônomas, a avaliação do nível de ruído de impacto nas coberturas acessíveis de uso coletivo não se aplica ao empreendimento em questão.

O cálculo do nível de pressão sonora de impacto padrão ponderado (L'nT,w) realizado pelo software Projetus leva em consideração o volume do ambiente receptor. Neste contexto, como ambos os quartos possuem o mesmo volume, selecionou-se àquele de número 01 como o ambiente representativo para a análise desse critério. As informações referentes à massa superficial $\left(\mathrm{kg} / \mathrm{m}^{2}\right)$ e ao $\mathrm{L}$ 'nT,w equivalente $(\mathrm{dB})$ foram definidas com base na biblioteca de materiais do Projetus [59] a partir da caracterização da espessura de cada componente do sistema (Tabela 11). A NBR 15.575/2013 estabelece o limite de $66 \leq \mathrm{L}$ 'nT, w $\leq 80 \mathrm{~dB}$ para o desempenho mínimo. No estudo de caso obteve-se como resultado o valor de $76,4 \mathrm{~dB}$ para L'nT,w. Verificase, portanto, que o sistema de piso para isolação de ruído de impacto especificado para o empreendimento atendeu ao mínimo exigido pela NBR 15.575/2013.

No que tange ao critério isolamento de ruído aéreo dos sistemas de pisos entre unidades avaliou-se o isolamento de som aéreo de ruídos de uso cotidiano (fala, TV, conversas, música, etc.) e uso eventual (áreas comuns e de uso coletivo). Neste contexto a NBR 15.575/2013 estabelece que, para o desempenho acústico mínimo, a diferença padronizada de nível ponderada (DnT,w) deve estar entre 45,0 e 49,0 dB, para sistema de piso de separação entre unidades habitacionais autônomas (UHA), em áreas em que um dos recintos seja dormitório. Após a definição dos elementos necessários para a análise do sistema, foi delineado o tipo de ligação no encontro entre eles bem como introduzido o valor de $20,81 \mathrm{~m}^{3}$ no software Projetus, referente ao volume do ambiente receptor. Como resultado estimou-se que $\mathrm{R}^{\prime} \mathrm{w}=47,3 \mathrm{~dB}$ para o índice de redução sonora ponderado e DnT,w= 46,7dB. Neste contexto, nota-se que o sistema de piso para isolação de ruído aéreo especificado para o empreendimento atendeu ao mínimo exigido pelo critério normativo analisado.

Para verificação dos níveis de ruído permitidos na habitação deve-se avaliar a diferença padronizada de nível ponderada promovida pela vedação externa (fachada e cobertura, no caso de casas térreas e sobrados, e somente fachada, nos edifícios multipiso). Assim, considerando que o empreendimento em questão localiza-se no entorno caracterizado pela classe II de ruído, o limite mínimo admissível para a diferença padronizada de nível ponderada a $2 \mathrm{~m}(\mathrm{D} 2 \mathrm{~m}, \mathrm{nT}, \mathrm{w})$ deve ser maior ou igual a $25 \mathrm{~dB}$, conforme requisitos estabelecidos na NBR 15.575/2013. Complementarmente, o valor de referência para Rw deverá ser maior ou igual a $30 \mathrm{~dB}$, para atingir o limite mínimo normativo estabelecido para sistemas de fachadas utilizados nas vedações externas dos dormitórios. Assim, para os dormitórios do apartamento 202 analisou-se as vedações formadas por alvenaria de blocos ( $\mathrm{P} 2$ e P4) bem como àquelas compostas por conjunto de alvenaria de blocos e esquadrias de alumínio (P1 e P3), conforme se observa na Figura 3.

O dimensionamento do índice de desempenho acústico de fachadas (D2m,nT,w) realizado pelo sof- 
tware Projetus considerou a interferência das esquadrias apenas para a análise acústica do sistema de vedação vertical externo (SVVE). Para tanto, foi introduzido manualmente no banco de dados do programa as informações técnicas da esquadria de alumínio especificado no projeto (janela de correr com 2 folhas da linha Beluno com 120x120mm e 1,44m² de área). A espessura do vidro (4mm) e nível de ruído da janela em $\mathrm{Rw}$ $(24 \mathrm{~dB})$ foi fornecido pelo fabricante (Alumasa) por meio de laudos técnicos do desempenho acústico de seus materiais. As informações referentes à área de fachada, $\mathrm{em} \mathrm{m}^{2}$, e ao volume do ambiente, em $\mathrm{m}^{3}$, foram extraídas do projeto. Ressalta-se que no valor referente à área da parede externa foi descontado o vão da esquadria de alumínio. No quesito transmissões laterais considerou-se os elementos de fachada não conexos, uma vez que estes não estão fortemente conectados aos elementos rígidos do interior como, por exemplo, os pavimentos e divisórias internas. Quanto à forma considerou-se a fachada plana com um valor de $\Delta \mathrm{Lfs}=0 \mathrm{~dB}$. Por fim, o isolamento acústico ponderado equivalente (Rw,equiv) das paredes externas foi obtido por meio da equação 8, demonstrada no item 1.2. Na Tabela 12 verifica-se os resultados dos índices obtidos para o SVVE P1, P2, P3 e P4 pelo software Projetus (R'w e D2m,nT,w) e, por equação específica (Rw,equiv).

Tabela 12: Dados de entrada para a análise dos níveis de ruído de ambos os quartos 01 do apartamento 202 x 102 .

\begin{tabular}{l|l|l|l|l|l}
\hline SVVE & ÁREA TOTAL $\left(\mathbf{m}^{\mathbf{2}}\right)$ & VOLUME DO AMBIENTE $\left.\mathbf{( m}^{\mathbf{3}}\right)$ & $\mathbf{R} \mathbf{w}(\mathbf{d B})$ & $\mathbf{D 2 m}, \mathbf{n T}, \mathbf{w}(\mathbf{d B})$ & Rw,equiv \\
\hline P1 & 8,24 & 20,81 & 31,20 & 30,40 & 31,00 \\
\hline P2 & 6,57 & 20,81 & 40,80 & 41,10 & 41,00 \\
\hline P3 & 6,57 & 20,81 & 30,30 & 30,50 & 30,00 \\
\hline P4 & 8,24 & 20,81 & 40,80 & 40,10 & 41,00 \\
\hline
\end{tabular}

Por meio da simulação computacional foram gerados os valores para D2m,nT,w e R'w ao passo que pelo método de cálculo estimou-se o valor de referência Rw. De forma geral, os valores aferidos em campo para o isolamento acústico (D2m,nT,w) tendem a ser inferiores aos obtidos em laboratório (Rw) devido às condições de contorno e aos métodos execução dos sistemas que podem influenciar e reduzir o resultado final [28]. Todavia, no presente estudo, os valores de Rw apresentados por ambos os métodos demonstraram semelhanças significativas confirmando os resultados encontrados em outros estudos $[34,36]$. Cumpre destacar que em virtude da variação dos limites normativos estabelecidos para D2m,nT,w e Rw, os níveis de desempenho acústico obtidos pelos dois métodos foram distintos. Deste modo, as paredes P1, P2, P3 e P4 apresentaram desempenho intermediário (I), superior (S), I e S, pelo método de simulação e, performance mínima (M), S, M e S, pelo método de cálculo, respectivamente. Verifica-se, portanto, que o método de cálculo apontou desempenho acústico inferior comparado àquele obtido pela simulação computacional. Todavia, em ambos os casos, os elementos em análise apresentaram desempenho acústico satisfatório para atenuação sonora perante as exigências estabelecidas pela NBR 15.575/2013, para a classe de ruído aplicável ao presente estudo.

No que tange aos níveis de ruído permitidos na habitação, a NBR 15.575/2013 estabelece meios para avaliar a diferença padronizada de nível ponderada $(\mathrm{DnT}, \mathrm{w})$ para ensaio de campo, promovida pela vedação entre ambientes. No presente estudo aplica-se os limites mínimos normativos de DnT,w entre 40 a $44 \mathrm{~dB}$ para paredes entre UHA (parede de geminação) nas situações nas quais não haja dormitório e, também, para conjunto de paredes e portas de unidades distintas separadas pelo hall (DnT,w obtida entre as unidades). O valor de referência mínimo de Rw para ambos os sistemas deverá estar entre 45 a 49dB. Na Figura 3 é possível identificar a parede que divide as salas de unidades distintas que foi objeto desta avaliação. A parede que separa a cozinha e área de serviço entre os apartamentos distintos não foi analisada por não se tratar de ambiente de permanência prolongada. Após a definição dos elementos necessários para a análise do sistema, foi inserido no programa o valor do volume do ambiente receptor, que no caso foi $31,22 \mathrm{~m}^{3}$.

Desta forma, o valor de R'w simulado para a parede que divide as salas de unidades distintas resultou em 39,30dB e, a DnT,w, 40,60dB. Por meio equação 7, apresentada no item 1.2 obteve-se $41,13 \mathrm{~dB}$ para o $\mathrm{Rw}$ de referência. Diferentemente da avaliação do critério anterior, os valores de Rw apresentados por ambos os métodos não foram tão próximos um do outro perfazendo uma diferença de 1,83dB. Além disso, pelo método de simulação, o valor de DnT,w foi ligeiramente maior do que aquele dimensionado para Rw, reforçando os resultados de estudos anteriores $[34,36] \mathrm{e}$, contrariando a afirmativa de que os valores do desempenho de isolamento acústico medidos em campo (DnT,w) tendem a ser inferiores aos obtidos em laboratório (Rw) [27]. Por fim, considerando a variação dos limites normativos, pela simulação computacional o sistema atingiu o desempenho acústico mínimo, ao passo que, pelo método de cálculo, o mínimo esperado de $45 \mathrm{~dB}$ não foi atendido. Neste contexto, adotou-se como resultado final o valor mais crítico, como margem de segurança. Desta forma, constatou-se, que o nível da isolação de ruído aéreo das paredes de geminação especificado para 
o empreendimento não atendeu aos limites normativos.

Para o outro sistema analisado, considerou-se o conjunto de parede e portas de duas unidades habitacionais, bem como, o ar contido no hall/corredor, delimitado por ambos os conjuntos (Figura 7). Diferentemente das análises anteriores, não foi possível determinar a isolação acústica do conjunto por meio de cálculo uma vez que o referencial teórico empregado neste estudo não contempla uma equação específica para esta finalidade. Desta forma, a DnT,w do conjunto foi estimada apenas pelo método de simulação. O volume do ambiente receptor considerado foi de $31 \mathrm{~m}^{3}$.

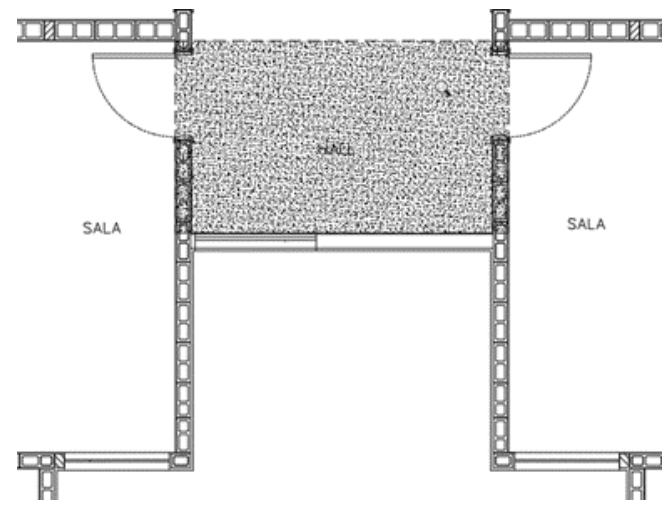

Figura 7: Conjunto de paredes e portas de unidades distintas separadas pelo hall a serem avaliados (Arquivo do acervo disponibilizado pela construtora, modificado pelo autor).

Como resultado obteve-se 47,1dB para o R'w e, 47,0 dB para o DnT,w. Desta forma, verificou-se que o nível da isolação de rú́do aéreo do conjunto de paredes das duas unidades habitacionais delimitados pelo ar contido no hall/corredor atendeu a exigência prevista na NBR 15.575/2013.

\section{DISCUSSÃO}

Os resultados apresentados no item 3 , indicaram necessidade de se alterar as especificações técnicas dos elementos de vedação vertical externos, uma vez que o valor mínimo de capacidade térmica (CT=130 $\left.\mathrm{kJ} /\left(\mathrm{m}^{2} . \mathrm{K}\right)\right)$ estabelecido na NBR 15.575/2013 não foi atendido. Ademais, o nível da isolação de ruído aéreo da parede de geminação entre unidades autônomas, sem a presença de dormitório, também não atingiu o critério mínimo exigido para o índice de redução sonora $(\mathrm{Rw}=45 \mathrm{~dB})$. Desta forma, foram propostas modificações nestes sistemas construtivos visando ao atendimento do desempenho térmico e acústico normativo.

Considerando os materiais constituintes das paredes externas, para elevar a CT propôs-se o acréscimo de uma camada de reboco de $10 \mathrm{~mm}$ de espessura entre a alvenaria de blocos cerâmicos e o revestimento de gesso corrido, na face interna. Tal escolha foi motivada pelas suas propriedades térmicas que se mostravam mais vantajosas para este propósito, em comparação com o gesso. Após os devidos ajustes, o método de cálculo indicou o atendimento do mínimo normativo perfazendo o valor de $\mathrm{U}=2,47 \mathrm{~W} /\left(\mathrm{m}^{2} \cdot \mathrm{K}\right)$ e $\mathrm{CT}=139$ $\mathrm{kJ} /\left(\mathrm{m}^{2} . \mathrm{K}\right)$. O ajuste se mostrou de fácil aplicação corroborando com os resultados de outros estudos que demonstram, em muitos casos, o atendimento dos sistemas testados em face aos limites mínimos estabelecidos para o desempenho térmico, conforme método simplificado da NBR 15.575/2013 [3, 11-13].

Para o atendimento do desempenho acústico da parede de geminação entre a sala das unidades habitacionais propôs-se aplicação de uma camada de reboco de $2,5 \mathrm{~cm}$ de espessura entre a alvenaria de blocos cerâmicos e o revestimento de gesso corrido, em ambas as faces do elemento. Também neste caso, as propriedades do reboco se mostraram mais favoráveis ao aumento do índice de redução sonora (Rw), em comparação com o gesso. Com auxílio do software Projetus, a parede divisória entre unidades habitacionais foi ajustada de modo a contemplar a nova camada de revestimento. Após o ajuste, a sua massa superficial foi de $256,15 \mathrm{~kg} / \mathrm{m}^{2}$. As especificações dos demais elementos adjacentes ao sistema principal modificado e suas respectivas áreas permaneceram as mesmas, bem como, o volume do ambiente receptor $\left(31,22 \mathrm{~m}^{3}\right)$ e as ligações presentes nas junções de todos os elementos. Os resultados da simulação indicaram os valores de 44,80dB para o R'w e, 46,10dB para o DnT,w. Por outro lado, o Rw estimado por meio da equação 7, demonstrada no item 1.2 , foi de $45,66 \mathrm{~dB}$.

Os números de Rw obtidos por ambos os métodos foram relativamente próximos um do outro perfazendo $0,86 \mathrm{~dB}$ de diferença. Contudo, o valor de $\mathrm{D} 2 \mathrm{~m}, \mathrm{nT}$, w gerado pela simulação foi maior que o dimensio- 
nado para $\mathrm{Rw}$, contrariando o princípio de que a quantia medida em campo (DnT,w) tendem a ser inferior àquela obtida em laboratório (Rw) [28] e, confirmando outros achados [34,36]. Avaliando os resultados finais, pelo método de simulação, o sistema atingiu o nível de desempenho acústico intermediário, ao passo que pelo método de cálculo foi possível atingir apenas o mínimo. Isso ocorreu devido ao fato de que o primeiro método caracterizou os níveis de desempenho dos elementos baseado nos valores de D2m,nT,w, contrapondo ao segundo item, que baseou a sua caracterização nos valores de Rw calculados. Como as exigência mínimas acústicas para D2m,nT,w e Rw são diferentes, os níveis de desempenho obtidos pelos dois métodos apresentaram variações. Porém, verifica-se que a parede que separa as unidades habitacionais distintas atendeu, em ambas as situações, ao desempenho mínimo estabelecido pela NBR 15.575/2013. Cumpre destacar que a modificação proposta neste sistema pode influenciar o cumprimento dos outros critérios normativos. Verificou-se, contudo, que no presente estudo tal modificação não foi relevante para melhorar o desempenho acústico dos outros sistemas analisados.

De forma geral, verificou-se que o método de simulação computacional e de cálculo empregados no presente trabalho para análise do isolamento sonoro em campo e laboratório, conduziu a resultados similares, apesar dos pormenores observados, de forma análoga a outros estudos presentes na literatura [34, 36]. Neste contexto, o software Projetus se mostrou eficaz como instrumento para a verificação do atendimento da NBR 15.575/2013, a exemplo de outros programas testados para este fim [46-48]. Assim como outros autores pontuaram, a simulação de parâmetros acústicos revelou-se como um importante referencial para auxiliar as análises dos sistemas construtivos [43] e subsidiar a tomada de decisão dos projetistas. A adequação do sistema construtivo do empreendimento analisado para o atendimento aos requisitos térmico e acústico normativos demandou pequenos ajustes confirmando os resultados obtidos por Klippel Filho et al (2018) que abordaram a influência da espessura de revestimentos de argamassa no desempenho acústico de alvenarias de blocos cerâmicos. Em suma, a aplicação do método normativo simplificado para verificação do desempenho térmico associada a análise acústica seja por meio de simulação e/ou cálculo, permitiu verificar as especificações e escolha dos sistemas construtivos possibilitando a análise de uma habitação de interesse social em fase de projeto / início de construção frente as exigências da NBR 15.575/2013.

\section{CONCLUSÕES}

No presente trabalho foi possível caracterizar os sistemas construtivos sujeitos às análises térmicas e acústicas previstas na NBR 15.575/2013 por meio da verificação de projeto padrão de moradia de interesse social. Para a avaliação do desempenho térmico do empreendimento adotou-se o método normativo simplificado, ao passo que para a análise acústica foram utilizados os métodos de simulação e de cálculo.

Os resultados indicaram que as paredes externas não atenderam ao valor mínimo de capacidade térmica exigido pela NBR 15.575/2013 ao passo que a parede de geminação entre unidades autônomas não atingiu o nível da isolação de ruído aéreo exigido. Neste contexto, propôs-se o acréscimo de uma camada de reboco para adequação destes sistemas às exigências térmicas e acústicas. Por meio de reavaliação, verificou-se o atendimento normativo dos sistemas em desconformidade.

No presente estudo investigou-se, ademais, a pertinência dos resultados simulados pelo software Projetus para os índices de desempenho acústico (DnT,w, D2m,nT,w, R'w e L'nT,w). Verificou-se, portanto, valores próximos àqueles de Rw determinados pelo método de cálculo. $\mathrm{O}$ valor de $\mathrm{DnT}$, w simulado foi igual ou ligeiramente maior do que aquele dimensionado para Rw, em alguns casos. Essa ressalva, contudo, não compromete a relevância dos resultados apresentados uma vez que as variações nos valores de DnT,w, $\mathrm{D} 2 \mathrm{~m}, \mathrm{nT}$,w e Rw não foram expressivas além de ter sido considerado para efeito de análise, a situação mais crítica.

O uso da simulação computacional com objetivo de emular e analisar o potencial desempenho acústico de determinada habitação permitiu realizar seu diagnóstico preliminar, gerando recomendações e ajustes nos seus sistemas construtivos. Tal fato colabora para o enriquecimento do banco de dados disponíveis aos responsáveis pelas especificações e tomada de decisão nos projetos. Esta estratégia, certamente, não dispensa os ensaios de campo servindo apenas como uma prévia do comportamento da edificação em face às exigências da NBR 15.575/2013. Assim, por meio deste recurso é possível implementar os devidos ajustes na edificação reduzindo intervenções, gastos futuros e retrabalhos para a adequação dos sistemas após a conclusão da obra.

No presente trabalho, a análise dos sistemas construtivos de habitação fundamentada na NBR 15.575/2013 se mostrou relevante, uma vez que colocou à disposição referencial de especificação edilícia em um determinado contexto climático e acústico. Grosso modo, o presente estudo alerta para a importância do tratamento acústico e térmico na fase inicial do projeto, uma vez que no presente trabalho duas variações de 
vedação vertical (externa e interna entre ambientes) não atenderam ao exigido pela NBR 15.575/2013, sem o devido ajuste nas especificações de seus materiais constituintes. Desta forma, a análise prévia do projeto passa a ser primordial, permitindo amenizar possíveis transtornos futuros indesejáveis. Como contribuição, este estudo apresenta diretrizes replicáveis para análise do atendimento estabelecido para o desempenho termo acústico normativo que poderão orientar a escolha dos projetistas. Os resultados ora obtidos poderão, portanto, fomentar alternativas para guiar a definição de sistemas construtivos que possam potencialmente apresentar conformidade em relação às exigências estabelecidas para o desempenho das habitações brasileiras. Como trabalho futuro sugere-se a análise aprofundada por meio de simulação do comportamento térmico edilício, bem como, aplicação do método de ensaio em campo de forma comparada com os resultados obtidos para os demais métodos estabelecidos pela NBR 15.575/2013 e /ou outro instrumento normativo e, também, avaliação da eficácia da predição acústica de outros softwares disponíveis para este propósito. Por fim, sugere-se que a escolha do empreendimento a ser analisado em campo seja pautada pelo rigor na execução dos serviços uma vez que a qualidade da mão de obra pode ser decisiva para obtenção de valores in situ semelhantes aos de laboratório. Neste contexto, a montagem e execução podem alterar uma condição teórica adequada para uma, na prática, inadequada, por isto a escolha deve se pautar nesta importante premissa ou considerar o efeito desta situação.

\section{BIBLIOGRAFIA}

[1] SANTOS, J. C. P., KOTHE, K. K., MOHAMAD, G., et al., "Comportamento térmico de fechamentos em alvenaria estrutural para a Zona Bioclimática 2 brasileira", Revista Matéria, v.20, n.2, pp 1019-1036, 2015.

[2] ASSOCIAÇÃO BRASILEIRA DE NORMAS TÉCNICAS - ABNT, "NBR 15.575: Edificações habitacionais - Desempenho", Rio de Janeiro, 2013.

[3] OLIVEIRA, R. D., SOUZA, R. V. G., MAIRINK, A. J. M., et al., "Concrete walls thermal performance analysis by Brazilian Standards", Energy Procedia, n. 78, pp 213-218, 2015.

[4] FERREIRA, C.C.; PEREIRA, I. M., "Avaliação de desempenho térmico de habitação de interesse social de acordo com a NBR 15.575, para as diversas zonas bioclimáticas" In: Anais do XIV Encontro Nacional de Tecnologia do Ambiente Construído (ENTAC), pp. 3590-3595, Juiz de Fora, out. 2012.

[5] Ministério das Cidades, DESEMPENHO TÉCNICO PARA HIS, http://app.cidades.gov.br/catalogo. Acessado em julho de 2018.

[6] INAD SP, MAPA DE RUÍDO URBANO - PROJETO PILOTO SP, http://www.mapaderuidosp.org.br. Acessado em setembro de 2018.

[7] INSTITUTO NACIONAL DE METROLOGIA - INMETRO, "Anexo da Portaria 50: Catálogo de Propriedades Térmicas de paredes, coberturas e vidros", Rio de Janeiro, 2013.

[8] Ministério de Meio Ambiente - MMA, PROJETEEE, http://projeteee.mma.gov.br. Acessado em abril de 2018.

[9] LAMBERTS, R., DUTRA, L., PEREIRA, F. O. R, "Eficiência Energética na Arquitetura", 3. ed., Rio de Janeiro, Eletrobras/PROCEL, 2014.

[10] ASSOCIAÇÃO BRASILEIRA DE NORMAS TÉCNICAS - ABNT, "NBR 15.220-3: Desempenho térmico de edificações - Parte 3: zoneamento bioclimático brasileiro e diretrizes construtivas para habitações unifamiliares de interesse social”, Rio de Janeiro, 2008.

[11] DUMKE, E.M.S, “Avaliação do desempenho térmico em sistemas construtivos da vila tecnológica de Curitiba como subsídio para a escolha de tecnologias apropriadas em habitação de interesse social", Dissertação de M.Sc., CEFETPR, Curitiba, PR, Brasil, 2002.

[12] KRÜGER, E. L., ZANNIN, P. H. T., "Avaliação termoacústica de habitações populares na vila tecnológica de Curitiba", Ambiente Construído, v. 6, n. 2, p. 33-44, abr./jun. 2006.

[13] CHVATAL, K. M. S., "Avaliação do procedimento simplificado da NBR 15575 para determinação do nível de desempenho térmico de habitações", Ambiente Construído, v. 14, n. 4, p. 119-134, out./dez. 2014.

[14] D'ELL SANTO, A., ALVAREZ, C. E., NICO-RODRIGUES, E. A., "Conforto e desempenho térmico em contradição na NBR 15575”, Cadernos do PROARQ, n.20, pp.115-136, dezembro 2013.

[15] SILVA, A. S.; GHISI, E. "Análise comparativa dos resultados do desempenho térmico da envoltória de uma edificação residencial pelos métodos de simulação do RTQ-R e da NBR 15575-1", Ambiente Construído, v. 14, n. 1, p. 213-230, jan./mar. 2014. 
[16] SORGATO, M. J., MELO, A. P., LAMBERTS, R., "Análise do método de simulação de desempenho térmico da norma NBR 15.575”, Paranoá, n. 12, pp. 13-22, 2014.

[17] SPANNENBERG, M. G., "Análise de desempenho térmico, acústico e lumínico em habitação de interesse social: estudos de caso em Marau-RS”, Dissertação de M.Sc., UFSC, Florianópolis, SC, Brasil, 2006.

[18] SILVA, A. S., ALMEIDA, L. S. S., GHISI, E. "Análise de incertezas físicas em simulação computacional de edificações residenciais", Ambiente Construído, v. 17, n. 1, p. 289-303, jan./mar.2017.

[19] OITICICA, M. L. G. R.; PENEDO, R. C. T., "Airborne sound insulation of vertical partitions in an apartment in Maceió - AL- Brazil”, In: Proceedings of the Euronoise, pp. 1879-1884, Maastricht, Jun. 2015.

[20] BORGES, R.M., "Análise de desempenho térmico e acústico de unidades habitacionais construídas no conjunto habitacional Beijamin Josá Cardoso em Viçosa-MG", Dissertação de M.Sc., UFV, Viçosa, MG, Brasil, 2013.

[21] ASSOCIAÇÃO BRASILEIRA DE NORMAS TÉCNICAS - ABNT, "NBR 10.152: Níveis de ruído para conforto acústico", Rio de Janeiro, 1987.

[22] ASSOCIAÇÃO BRASILEIRA DE NORMAS TÉCNICAS - ABNT, "NBR 12.179: Tratamento Acústico em Recintos Fechados", Rio de Janeiro, 1992.

[23] ASSOCIAÇÃO BRASILEIRA DE NORMAS TÉCNICAS - ABNT, "NBR 10.151: Avaliação do ruído em áreas habitadas", Rio de Janeiro, 2000.

[24] CÂMARA BRASILEIRA DA INDÚSTRIA DA CONSTRUÇÃO - CBIC, Desempenho de edificações habitacionais: guia orientativo para atendimento à norma ABNT NBR 15575/2013, Fortaleza, CBIC, 2013.

[25] INTERNATIONAL ORGANIZATION FOR STANDARDIZATION - ISO, "ISO 15.712/2005: Building acoustics - Estimation of acoustic performance of buildings from the performance of elements", Geneva, 2005.

[26] THE EUROPEAN COMMITTEE FOR STANDARDIZATION - CEN, "EN 12.354/2000: Building acoustics - Estimation of acoustic performance in buildings from the performance of elements", Brussels, 2000.

[27] CUNHA, I., LEMOS, E., HOLTZ, M., et al., "Guidelines for noise classification methods of residential buildings, according to Brazilian standard ABNT NBR 15575-4" In: International Congress on Acoustics, pp. 1-8, Buenos Aires, Sept. 2016.

[28] PIERRARD, J. F., AKKERMAN, D, "Manual ProAcústica sobre a Norma de Desempenho", 2a ed., São Paulo, Rush Gráfica e Editora Ltda., 2015.

[29] ASSOCIAÇÃO BRASILEIRA DE NORMAS TÉCNICAS - ABNT, "NBR 10.151/2000: Acústica Avaliação do ruído em áreas habitadas, visando o conforto da comunidade - Procedimento", Rio de Janeiro, 2000.

[30] SECRETARIA NACIONAL DE HABITAÇÃO - SNH "Especificações de desempenho nos empreendimentos de HIS baseadas na ABNT NBR 15575 - Edificações Habitacionais - Desempenho", Brasília, SNH, 2015.

[31] NUNES, M.F.O., ZINI, A., PAGNUSSAT, D.T., "Desempenho Acústico de Sistemas de Piso: Estudos de Caso Para Isolamento ao Ruído Aéreo e de Impacto", Acústica e Vibrações, n. 46, pp.13-19, dezembro 2014.

[32] Portal Acústica, CONTRAPISO FLUTUANTE: chega de ruído, http://portalacustica.info/tag/ruido-deimpacto/. Acessado em novembro 2017.

[33] NETO, M. F. F., BERTOLI, S. R., "Desempenho acústico de paredes de blocos e tijolos cerâmico: uma comparação entre Brasil e Portugal", Ambiente Construído, Porto Alegre, v. 10, n. 4, p. 169-180, out./dez. 2010.

[34] FERREIRA, J. A. C., ZANNIN, P. H. T., "Determinação de coeficientes de isolamento acústico: medições in situ e simulação computacional", Ambiente Construído, Porto Alegre, v. 7, n. 2, p. 15-29, abr./jun. 2007.

[35] MARTINS, L. A. C., SAHB, C. A. S., "Conforto acústico de apartamentos residenciais, quanto ao ruído de impacto", In: Anais da I Conferência latino-americana de construção sustentável e Encontro nacional de tecnologia do ambiente construído - ENTAC, pp. 1-15, São Paulo, Jul. 2004. 
[36] NETO, M. F. F., BERTOLI, S. R., BARRY, P. J., "Diferença entre testes de desempenho acústico em laboratório e campo em paredes de alvenaria”, In: Anais do XXIII Encontro da Sociedade Brasileira de Acústica, pp.1-8, Salvador, Maio 2010.

[37] FERREIRA, D. P. F., MICHALSKI, R. L. X. N., CASTRO, A. O. S., "Metodologia para expressão da incerteza na medição de isolamento sonoro", Cadernos do IME - Série Estatística, Rio de Janeiro, v.26, p.113, 2009.

[38] MICHALSKI, R. L. X. N., "Metodologias para medição de isolamento sonoro em campo e para expressão da incerteza de medição na avaliação do desempenho acústico de edificações”, Tese de D.Sc., COPPE/UFRJ, Rio de Janeiro, RJ, Brasil, 2011.

[39] DUARTE, E. A. C., VIVEIROS, E. B., "Desempenho acústico na arquitetura residencial brasileira: paredes de vedação", Ambiente Construído, Porto Alegre, v. 7, n. 3, p. 159-171, jul./set. 2007.

[40] SALES, U. C., SOUZA, H. A., NEVES, F. A., "Avaliação comparativa do desempenho acústico de painéis de vedação pré-fabricados", In: Anais do VI Encontro Nacional e III Encontro Latino-Americano sobre Conforto no Ambiente Construído - ENCAC, pp. 1-7, São Pedro, Nov. 2001.

[41] NETO, N. A. S., "Caracterização do isolamento acústico de uma parede de alvenaria estrutural de blocos cerâmicos”, Dissertação de M.Sc., UFSM, Santa Maria, RS, Brasil, 2006.

[42] PAIXÃO, D. X., "Caracterização do isolamento acústico de uma parede de alvenaria utilizando Análise Estatística de Energia - SEA”, Tese de D.Sc., UFSC, Florianópolis, SC, Brasil, 2002.

[43] RIBAS, R. A. J., SOUZA, H. A., ADRIANO, J. J., et al., "Desempenho térmico e acústico de painéis de fechamento em multicamadas”, Revista Eletrônica de Engenharia Civil, v.6, n.2, pp.1-10, 2013.

[44] SILVA JÚNIOR, O. J., RÊGO SILVA, J. J., PINHEIRO, M. A. S., "Desempenho acústico de divisórias verticais em blocos de gesso: uma avaliação em campo e laboratório", Pesquisa em Arquitetura e Construção - PARC, Campinas, v. 5, n. 2, p. 15-21, jul./dez. 2014.

[45] KLIPPEL FILHO, S., TUTIKIAN, B. F., OLIVEIRA, M. F., et al., "Influência da espessura de revestimentos de argamassa no desempenho acústico de alvenarias de blocos cerâmicos", Ambiente Construído, Porto Alegre, prelo. 2018.

[46] TAKAHASHI, V. F. M., "Desempenho acústico de edificações: ferramenta computacional para avaliação”, Tese de D.Sc., Unicamp, Campinas, SP, Brasil, 2016.

[47] FILHO, V. M. S., SPOSTO, R. M., CALDAS, L. R., “Análise do desempenho acústico de fachadas ventiladas de porcelanato à luz da norma de desempenho: estudo de caso em um edifício habitacional em Brasília-DF”, Revista Eletrônica de Engenharia Civil, v.13, n.2, pp.116-130, 2017.

[48] NETO, M. F. F., BERTOLI, S. R., "Conforto acústico entre unidades habitacionais em edifícios residenciais de São Paulo, Brasil”, In: Anais da Acústica, pp.1-10, Coimbra, Out. 2008.

[49] Congresso Brasileiro de Meteorologia, ANAIS 1980-2006: PALAVRA-CHAVE, http://www.cbmet.org.br/cbm-files/14-02b163ebfb99f5d2d9c1c111e80b5509.pdf. Acessado em junho de 2019.

[50] Câmara Municipal de Belo Horizonte - Estado de Minas Gerais, LEI 7166/1996, https://www.cmbh.mg.gov.br/atividade-legislativa/pesquisar-legislacao/lei/7166/1996. Acessado em junho de 2019.

[51] Google Maps, PESQUISE NO GOOGLE MAPS, https://www.google.com.br/maps. Acessado em agosto de 2017.

[52] Câmara Municipal de Contagem - Estado de Minas Gerais, PLANO DIRETOR DE CONTAGEM 2017, http://www.cmc.mg.gov.br/?page_id=9716. Acessado em agosto de 2017.

[53] Roriz Bioclimática, ZBBR - ZONEAMENTO BIOCLIMÁTICO DO BRASIL, http://www.roriz.eng.br/download_6.html. Acessado em agosto de 2017.

[54] ASSOCIAÇÃO BRASILEIRA DE NORMAS TÉCNICAS - ABNT, "NBR 15.220: Desempenho térmico de edificações - Parte 3: zoneamento bioclimático brasileiro e diretrizes construtivas para habitações unifamiliares de interesse social”, Rio de Janeiro, 2008.

[55] LEI COMPLEMENTAR Nº82/2010, ANEXO 9 - MAPA DE HIERARQUIZAÇÃO DO SISTEMA VIÁRIO, www.contagem.mg.gov.br/arquivos/legislacao/dec_-_953_anexo.pdf. Acessado em agosto de 2017. 
[56] Câmara Municipal de Belo Horizonte - Estado de Minas Gerais, LEI 4.253/1985,

https://www.cmbh.mg.gov.br/atividade-legislativa/pesquisar-legislacao/lei/4253/1985. Acessado em agosto de 2017.

[57] Câmara Municipal de Belo Horizonte - Estado de Minas Gerais, DECRETO 5.893/1988, https://www.cmbh.mg.gov.br/atividade-legislativa/pesquisar-legislacao/decreto/5893/1988. Acessado em agosto de 2017.

[58] Liz Serviços Online, LEI 3.789/2003, https://leismunicipais.com.br/a/mg/c/contagem/leiordinaria/2003/379/3789/lei-ordinaria-n-3789-2003-dispoe-sobre-a-politica-municipal-do-meio-ambienteseus-fins-e-mecanismos-de-aplicacao-e-da-outras-providencias. Acessado em agosto de 2017.

[59] Projetus, MANUAL DE USO, multinova.ind.br/imagens/download/manual-de-uso-projetus.pdf. Acessado em abril de 2017.

\section{ORCID}

Paula Capanema Silva Carneiro https://orcid.org/0000-0002-0861-9065

Raquel Diniz Oliveira

https://orcid.org/0000-0003-3712-4499 